\title{
DOSSIER
}

\section{"ESPAÑA NO ERA RUSIA" LA REVOLUCIÓN ESPAÑOLA DE 1917: ANATOMÍA DE UN FRACASO}

\author{
Francisco J. Romero Salvadó \\ University of Bristol \\ f.romerosalvado@bristol.ac.uk
}

Recibido: 29/06/2016 - Aceptado: 13/10/2016

\author{
"Spain was not Russia" \\ The Spanish Revolution of 1917: \\ Anatomy of a Failure
}

Cómo citar este artículo/Citation:

Francisco J. ROMERO SALVADÓ (2017), “España no era Rusia” La revolución española de 1917: Anatomía de un fracaso", Hispania Nova, 15, págs. 416-442,

DOI: https://doi.org/10.20318/hn.2017.3496
Copyright: (c) HISPANIA NOVA es una revista debidamente registrada, con ISSN 1138-7319 y Depósito Legal M 9472-1998. Los textos publicados en esta revista están -si no se indica lo contrario- bajo una licencia Reconocimiento-Sin obras derivadas 3.0 España de Creative Commons. Puede copiarlos, distribuirlos y comunicarlos públicamente siempre que cite su autor y la revista y la institución que los publica y no haga con ellos obras derivadas. La licencia completa se puede consultar en: http://creativecommons.org/licenses/by-nd/3.0/es/deed.es
Resumen: Este artículo analiza la crisis de modernidad del régimen de la Restauración dentro de la dinámica general revolucionaria propiciada por la I Guerra Mundial. En este sentido, el caso español (con sus connotaciones peculiares) es examinado como la versión regional de la quiebra general del orden socio-político europeo dominado por monarquías constitucionales y parlamentarias pero de corte elitista y clientelar.

La neutralidad salvó a España de la sangría humana pero no la pudo aislar de su enorme impacto socio-económico y político. La combinación en 1917 de factores de índole externa (ideológica polarización en torno a la neutralidad, revolución rusa) y doméstica (carestía de la vida, crisis de subsistencias, dislocación social) desembocaron en un ciclo reformista/revolucionario que sin embargo terminó en fracaso. Este artículo examina las condiciones y razones (agentes y circunstanciales) que explican tal fracaso así como el coste en que incurrió el régimen para garantizar su supervivencia. Dentro de estos parámetros, las peculiaridades del ciclo revolucionario español se analizan comparando con los rasgos diferenciales del modelo ruso.

Palabras Clave: Primera Guerra Mundial, Neutralidad, revolución, Juntas, asamblea, Alfonso XIII, zarismo, Lenin.
Abstract: This article analyses the crisis of modernity of Spain's Restoration regime as part of the revolutionary dynamic spurred by the First World War. Within this context, the Spanish case (with its obvious particular connotations) is examined as the regional version of the breakdown of the traditional European socio-political order then dominated by constitutional and parliamentarian monarchies although elitist or clientelist in nature.

Her neutrality spared Spain from the human slaughter but could not isolate her from the war's huge socioeconomic and political impact. The combination in 1917 of factors both external (ideological polarization, Russian revolution) and domestic (shortages of basic products, rising prices, social dislocation) led to a reformist/revolutionary cycle that nevertheless ended in utter failure. This article examines the conditions and reasons (agential and accidental) that explain such failure as well as the price that the regime had to pay to guarantee its survival. Within these parameters, the peculiarities of the Spanish revolutionary cycle are analysed in comparative terms with the differential features of the Russian model.

Key words: First World War, neutrality, revolution, Juntas, assembly, Alfonso XIII, Tsarism, Lenin 


\section{"España no era Rusia" \\ La revolución española de 1917: Anatomía de un fracaso}

Dentro del marco general de la Gran Guerra, el año 1917 constituyó un punto de inflexión. Tras tres años de cataclismo, l'union sacrée en los países beligerantes comenzó a resquebrajarse. La matanza de la crema de la juventud europea junto a la creciente miseria socio-económica transformó la fiebre patriótica inicial en movimientos de protesta popular que cuestionaban la autoridad de las clases dirigentes. Al mismo tiempo, la irrupción de los Estados Unidos y la Unión Soviética en el orden internacional presagiaba el final de la hegemonía mundial de las grandes potencias europeas ${ }^{1}$.

El impacto sísmico de la Gran Guerra traspasó las fronteras de los países beligerantes, afectando a los neutrales y, por supuesto, a España. Sin embargo, como señaló Manuel Espadas Burgos en el año 2000, es uno de los capítulos de nuestra historia contemporánea más necesitado de investigación ${ }^{2}$. Esta relativa deficiencia se ha ido progresivamente corrigiendo. Es muy posible que veamos una avalancha de nueva literatura con motivo del centenario como ha sucedido en el pasado con otros acontecimientos (el desastre colonial de 1898, la Semana Trágica de 1909, etc.). Se han celebrado numerosos congresos y visto la luz excelentes trabajos que abarcan la cultura, la economía y, sobre todo, las relaciones internacionales ${ }^{3}$. Hoy conocemos con detalle la injerencia de los países beligerantes

\footnotetext{
${ }^{1}$ Arno MAYER, Political Origins of the New Diplomacy, Londres, Vintage, 1970, pp. v-vi.

2 Manuel ESPADAS BURGOS, “España y la Primera Guerra Mundial”, Javier TUSELL, Juan AVILÉS y Rosa PARDO (coords.), La política exterior de España en el siglo XX. Madrid, Biblioteca Nueva, 2000, p. 97. Ver también Maximiliano FUENTES CODERA, “Presentación”, Ayer, 91 (2013), pp. 21-23 y Carolina GARCíA SANZ, "La Gran Guerra en su centenario", Ayer, 95 (2014), pp. 252-253. No fue hasta 2002 que apareció la primera y, hasta la fecha, única monografía del tema en toda su complejidad y contexto: Francisco J. ROMERO SALVADÓ, España 1914-18, Entre la Guerra y la revolución, Barcelona, Crítica, 2002 (traducción de Spain 1914-18: Between the War and the Revolution, Londres, Routledge, 1999). Las tesis de este libro fueron actualizadas y ampliadas para cubrir los años hasta el golpe militar de 1923 en The Foundations of Civil War. Revolution, Social Conflict and Reaction in Spain, Londres, Routledge, 2008.

${ }^{3}$ El estado de la cuestión en Maximiliano FUENTES CODERA y CAROLINA GARCÍA SANZ, “España y la Gran Guerra: un análisis historiográfico a la luz del centenario", Índice Histórico Español, 128 (2015), pp. 97-130. Un resumen de publicaciones desde 2002 debe incluir: Juan PANDO, Un rey para la esperanza: La España humanitaria de Alfonso XIII en la Gran Guerra, Madrid, Temas de hoy, 2002; Javier PONCE MARRERO, Canarias en la Gran Guerra, 19141918, Tenerife, Cabildo de Gran Canaria, 2006; Carolina GARCÍA SANZ, La Primera Guerra Mundial en el Estrecho de Gibraltar. Economía, política y relaciones internacionales, Madrid, CSIC, 2012; Rosa PARDO, "España ante el conflicto bélico de 1914-1918: ¿Una espléndida neutralidad?”, Salvador FORNER (ed.), Coyuntura Internacional y Política Española, Madrid, Biblioteca Nueva, 2010; Miguel Ángel MARTORELL, "No fue aquello solamente una guerra, fue una revolución: España y la Primera Guerra Mundial", Historia y Política, 26 (2011); Eduardo GONZÁLEZ CALLEJA y Paul AUBERT, Nidos de espías. España, Francia y la I Guerra Mundial, Madrid, Alianza, 2014;
}

HISPANIA NOVA., 15 (2017), págs. 416-442

DOI: https://doi.org/10.20318/hn.2017.3496 
en España, sus redes de espionaje, las actividades de los submarinos, etc. En el caso particular del año 17, la falta de estudios contrasta con la importancia que le reconoce la historiografía. De hecho, trabajos relativamente antiguos siguen siendo de obligada referencia: por ejemplo, el pionero texto de Juan Antonio Lacomba y las secciones relevantes de los estudios de Carolyn P. Boyd y Gerald Meaker sobre las fuerzas armadas y el movimiento obrero respectivamente ${ }^{4}$.

Siguiendo el esquema inicialmente esbozado por el escritor Fernando Soldevilla, Lacomba sugiere que España vivió en 1917 un ciclo revolucionario en tres fases: mesocrática (junio), burguesa (julio) y proletaria (agosto). Aceptando en líneas generales tal periodización, pero cuestionando su determinismo socio-económico, este artículo avanza nuevas reflexiones siguiendo la dirección emprendida en recientes publicaciones que enfatizan la existencia de una fase paralela de reacción gubernamental que acabó dictando la agenda y el factor comparativo con el caso de Rusia ${ }^{5}$. Aunque útil metodológicamente, tal periodización, además, oscurece la complejidad de un proceso que transciende ampliamente este marco cronológico. Como Jonathan Smele subraya en su estudio sobre la revolución rusa, aunque por su magnitud los acontecimientos de este año suelen situarse en el centro de cualquier estudio del periodo, no debe olvidarse que formaron parte de un antes y después. El principio y el final tienden a ser nociones vagas que basadas en la confluencia de diversos eventos son convenientemente tildadas de épocas históricas ${ }^{6}$.

Sin ignorar sus idiosincrasias, cualquier estudio del ciclo revolucionario y la paralela crisis del régimen liberal español deben partir de la premisa que no fue un caso excepcional en Europa sino la variante local de la crisis de modernidad causada por la irrupción de la sociedad de masas y cuyo catalizador fue la Gran Guerra. Según Martin Blinkhorn, las clases gobernantes de buena parte del

Fernando GARCÍA SANZ, España en la Gran Guerra. Espías, diplomáticos y traficantes, Madrid, Galaxia Gutenberg, 2014; Maximiliano FUENTES CODERA, España en la Primera Guerra Mundial: una movilización cultural, Madrid, Akal, 2014; Francisco MORENTE y Javier RODRIGO (eds.), Tierras de nadie. La Primera Guerra Mundial y sus consecuencias, Granada, Comares, 2014.

4 Juan Antonio LACOMBA, La crisis española de 1917, Málaga, Ciencia Nueva, 1970; Gerald MEAKER, The Revolutionary Left in Spain 1914-23, Stanford, Stanford University Press, 1974; Carolyn P. BOYD: Praetorian Politics in Liberal Spain, Chapel Hill, University of North Carolina Press, 1979. A ellos debe añadirse Carlos FORCADELL, Parlamentarismo y bolchevización: El Movimiento Obrero Español 1914-1918, Barcelona, Crítica, 1978; Jacinto MARTíN, La huelga de 1917, Madrid, Zero, 1971; y algunas síntesis como la del mismo LACOMBA, "España en 1917. Ensayo de morfología de una crisis histórica", Saitabi, no. 18 (1968); Joan SERRALLONGA, "Motines y revolución. España, 1917", Ayer, no. 4 (1991). Naturalmente, existen obras de gran interés de contemporáneos de los hechos como Fernando SOLDEVILLA, Tres revoluciones. Apuntes y notas. La junta de reforma. La asamblea parlamentaria. La huelga general, Madrid, Julio Cosano, 1917; José Buxadé, España en crisis. La bullanga misteriosa de 1917, Barcelona, Bauzá, 1917; Mauro BAJATIERRA, Desde las barricadas. Una semana de revolución en España. Las jornadas de Madrid en Agosto de 1917, Tortosa, Monclús, 1918; Manuel BURGOS Y MAZO, Páginas históricas de 1917, Madrid, Núñez Samper, 1918; Andrés SABORIT, La huelga de agosto de 1917, México, Pablo Iglesias, 1967.

${ }^{5}$ Ver trabajos de Francisco J. ROMERO SALVADÓ, “El Arte de la Insurrección. Análisis crítico y comparado de dos ciclos revolucionarios paralelos (España y Rusia, Marzo-Noviembre 1917)", Carmen FRÍAS, José Luis LEDESMA y Javier RODRIGO (eds.), Reevaluaciones. Historias locales y miradas globales, Zaragoza, Institución Fernando el Católico, 2011; “La crisis revolucionaria española de 1917: una apuesta temeraria”, Francisco J. ROMERO SALVADÓ y Angel SMITH (eds.), La Agonía del Liberalismo español. De la revolución a la dictadura, 1913-1923, Comares, Granada, 2014.

${ }^{6}$ Jonathan D. SMELE, The Russian Civil Wars. The Years that Shook the World, Londres, Hurst \& Company, 2015, pp. 1,8 .

HISPANIA NOVA., 15 (2017), págs. 416-442

DOI: https://doi.org/10.20318/hn.2017.3496 
continente europeo tuvieron que enfrentarse a la avalancha de demandas por reformas sociales, genuina democratización e incluso la temida revolución socialista ${ }^{7}$. Dentro de esa dinámica, el colapso del zarismo y la erección del régimen soviético en 1917 anunciaron el comienzo de un periodo de radicalización social que algunos autores han descrito como una guerra civil europea o crisis de 30 años del Siglo $X^{8}$.

La neutralidad salvó a España de la hecatombe humana y material del conflicto pero no la aisló de su profundo impacto. El agrio enfrentamiento entre dos visiones contrapuestas sobre los principios en que debía sustentarse el país y la convulsión socio-económica aceleraron la crisis de un régimen liberal pero oligárquico. Como el título de este artículo indica, el ciclo revolucionario español se cerró con un sonoro fracaso; un fracaso que, sin embargo, con la excepción de Rusia, fue la norma en Europa. Entre la caída del zarismo en marzo y la toma del poder por los Bolcheviques en noviembre ${ }^{9}$, la revolución en España careció de la energía espontánea de la primera y, desde luego, de la eficacia clínica de la segunda. Su análisis demuestra que a diferencia de Rusia, no existieron las condiciones objetivas ni propicias para el triunfo insurreccional. Además, la astucia de las clases gobernantes contrastó dramáticamente con el amateurismo e incluso contradicciones de las fuerzas opuestas al régimen. El epílogo de ambos casos aunque muy diferente tenía algo crucial en común: el año 17 sólo era la antesala de un periodo de violencia social en una escala inédita.

\section{EL CREPÚSCULO DE UNA ERA}

La Gran Guerra representó el crepúsculo de una era: la violenta irrupción de un nuevo siglo marcado por el protagonismo de las masas y el fin del universo elitista que había gobernado Europa hasta 1914. El impacto devastador del conflicto aceleró el proceso de trasformación socio-económica e impulsó a amplios sectores sociales en dirección a la democracia reformista o la revolución socialista. EI año 1917 marcó un precedente histórico: la caída en Rusia del régimen más autocrático del continente seguido meses después por el triunfo de un partido marxista revolucionario. Un testigo presencial, el periodista norteamericano John Reed tituló su narración de este episodio "Diez días que estremecieron al mundo"10. El fenómeno revolucionario ruso constituía un experimento social inédito que causó simultáneamente terror como esperanzas y en cuyas reverberaciones pueden trazarse los momentos determinantes del Siglo XX: desde las resoluciones del Tratado de Versalles hasta la Guerra Fría ${ }^{11}$.

\footnotetext{
${ }^{7}$ Martin BLINKHORN, 'Introduction: Allies, Rivals or Antagonists? Fascists and Conservatives in Modern Europe, Martin BLINKHORN (ed.), Fascists and Conservatives, Londres, Unwin Hyman, 1990, p. 3.

${ }^{8}$ Arno, MAYER, La persistencia del antiguo régimen. Europa hasta la Gran Guerra, Madrid, Alianza, p. 14; Helen GRAHAM y Paul PRESTON (eds.), The Popular Front in Europa, Londres, Macmillan 1987, p. 1; Richard BESSEL, "Politics", Julian JACKSON (ed.), Europe 1940-1945, Oxford, OUP, 2002.

${ }^{9}$ Utilizamos por razones de coherencia narrativa el Calendario Gregoriano usado por el resto de Europa desde su adopción por el Papa Gregorio XIII en 1582 en vez del entonces en vigor en Rusia Calendario Juliano, que (en el siglo 20) iba trece días detrás. Según el Calendario Juliano, la revolución que derribó al zar tuvo lugar entre el 26 de febrero y el 2 de marzo de 1917 y la que llevó al poder a los Bolcheviques, el 25 de octubre de 1917. El gobierno soviético aceptó el Calendario Gregoriano en enero de 1918.

10 John REED, Ten Days that Shook the World, Londres, Penguin, 1977 [1919\}. Reed viajó a Rusia donde abrazó la ideología del nuevo régimen soviético y murió de tifus en 1920.

${ }^{11}$ Jonathan D. SMELE, The Russian..., op. cit., pp. 1-2.
}

HISPANIA NOVA., 15 (2017), págs. 416-442

DOI: https://doi.org/10.20318/hn.2017.3496 
En España, tras la Restauración Borbónica en diciembre de 1874, el sistema institucionalizado por Antonio Cánovas constituyó un claro avance con respecto a las décadas anteriores. Inició una era de estabilidad basada en la alternancia (turno pacífico) en el ejecutivo de dos partidos dinásticos (Liberal y Conservador) en el marco de una monarquía parlamentaria de carácter liberal que consagraba derechos civiles básicos como la libertad de expresión y reunión, e incluso desde 1890 el sufragio universal masculino. Pero, el "encanto" de la Restauración tenía sus límites. Como indica Gabriel Cardona, la política era un juego de notables donde la mayoría de los ciudadanos no tenían ni arte ni parte ${ }^{12}$. Tanto Conservadores como Liberales no eran partidos de masas sino comités de notables cuya cohesión interna se basaba en lazos familiares y redes clientelares. Los gobiernos manufacturaban los resultados de las elecciones por medio de los caciques locales lo que en la práctica representaba la efectiva inhabilitación de grandes sectores de la población ${ }^{13}$. Sin embargo, como apuntan estudios recientes, debe superarse el esquematismo tradicional que reducía la Restauración a meramente un sistema estático y fraudulento que perpetuó el retraso socio-económico. En realidad, presidió una época de rápida modernización. Además, se trataba de un régimen constitucional dispuesto a integrar aquellos grupos dispuestos a aceptar la legitimidad monárquica vigente ${ }^{14}$. Como sugiere Ramón Villares, la Restauración era la variante local del sistema universal de clientelismo político; un fenómeno asociado con regímenes políticos representativos, pero con una ciudadanía poco desarrollada y una cultura política poco participativa ${ }^{15}$.

Una lacra particular de la Restauración fue la supervivencia del pretorianismo con su claro potencial desestabilizador, algo crucial para entender el desenlace de la crisis de 1917. Si bien Cánovas consiguió desterrar el pronunciamiento militar como árbitro final de cambio político al ofrecer un mecanismo constitucional para la alternancia en el poder no es cierto que consolidase la preponderancia civilista en el estado. El miedo al "despotismo de las masas" frenó cualquier idea de reformar el ejército o subordinarlo a la autoridad civil. Los gobiernos solían responder a la agitación social con la suspensión de las garantías constitucionales y la declaración del estado de guerra lo que equivalía su renuncia al control del orden público en favor de un modelo militarizado ${ }^{16}$. El resultado fue la consolidación de un poder prácticamente autónomo. Además, a pesar de su asfixiante peso en el presupuesto estatal, la mayor parte del gasto militar iba destinado a pagar los sueldos de los oficiales

\footnotetext{
12 Gabriel CARDONA, Alfonso XIII, el rey de espadas, Barcelona, Planeta, 2010, p. 27.

${ }^{13}$ Un estudio exhaustivo del poder caciquil en José VARELA ORTEGA (coord.), El poder de la influencia. Geografía del caciquismo en España, 1875-1923, Madrid: Marcial Pons, 2001. Un análisis brillante de sus diferentes facetas en Antonio ROBLES EGEA (ed.), Política en penumbra. Patronazgo y clientelismos políticos en la España contemporánea, Madrid, Siglo XXI, 1996.
}

${ }^{14}$ Mercedes CABRERA y Fernando del REY, "De la Oligarquía y el caciquismo a la política de intereses. Por una relectura de la Restauración", Manuel SUÁREZ CORTINA (ed.), Las máscaras de la libertad, Madrid, Marcial Pons, 2003; Javier MORENO LUZÓN, Modernizing the Nation. Spain during the Reign of Alfonso XIII, 1902-1931, Brighton, Sussex Academic Press, 2012, pp. 1-6.

${ }^{15}$ Ramón VILLARES, “Alfonso XII y Regencia”, Ramón VILLARES y Javier MORENO LUZÓN, Historia de España, Vol. VII: Restauración y Dictadura, Barcelona, Crítica/Marcial Pons, 2009.

${ }^{16}$ Ver los trabajos de Eduardo GONZÁLEZ CALLEJA: La razón de la fuerza. Orden público, subversión y violencia política en la España de la Restauración, 1875-1917, Madrid, CSIC, 1998, pp. 55-72 y “El ejército y el problema del orden público, 1875-1936", Jean Claude RABATÉ, L'armée dans la société espagnole, Nantes, Édition du Temps, 2003, p. 135.

HISPANIA NOVA., 15 (2017), págs. 416-442

DOI: https://doi.org/10.20318/hn.2017.3496 
perpetuando así un ejército enfermo crónico de hipertrofia y, consecuentemente, retrasado en términos de modernización e infraestructura con respecto a sus rivales ${ }^{17}$

Al mismo tiempo, el marco constitucional sellando el principio de soberanía nacional compartido por el monarca y las Cortes facilitaba la interferencia de aquél en la política cotidiana. La persistencia del turno significaba que la corona, al otorgar el decreto de disolución de Cortes a quien consecuentemente iba a fabricar las nuevas elecciones, y no el pueblo a través de comicios parlamentarios, era el auténtico árbitro de la vida pública. Dada la naturaleza de los partidos gobernantes, las luchas intestinas eran frecuentes. La llegada al trono de Alfonso XIII en 1902, coincidente con la desaparición de los primeros jefes históricos (Antonio Cánovas del Partido Conservador y Práxedes Mateo Sagasta del Liberal), facilitó al joven soberano, cuyo afán de protagonismo fue evidente desde el principio, la posibilidad de derribar o imponer gabinetes ${ }^{18}$. De hecho, muchas crisis ministeriales se las tildó de "orientales", pues eran manufacturadas en el Palacio de Oriente, la residencia del rey19. Además, la identificación de Alfonso XIII con sus oficiales en sus disputas con los políticos contribuyó gradualmente a erosionar los cimientos del régimen. Cánovas había querido convertir al monarca en un soldado-rey para que disciplinase al ejército. Alfonso XIII se convirtió en un Rey-Soldado; o, según Gabriel Cardona, un "Rey de Espadas" cuyo apoyo a la existencia de un poder militar casi autónomo descarnó la autoridad del estado ${ }^{20}$. La Ley de Jurisdicciones de 1906, a partir de la cual los tribunales militares ampliaban sus facultades sobre los civiles, reflejó con claridad la fragilidad de la supremacía civil y la alianza del trono con sus oficiales del ejército a expensa de los políticos. $^{21}$

\footnotetext{
${ }^{17}$ En 1900, habían 499 generales, 578 coroneles y unos 23.000 oficiales para un ejército de 80,000 hombres (seis veces más oficiales que en Francia que contaba con un ejército de 180.000 soldados). Las cifras están en Carlos SECO SERRANO, Militarismo y civilismo en la España contemporánea, Madrid, IEC, 1984, p. 233. Ver también, Gabriel CARDONA: El poder militar en la España contemporánea hasta la guerra civil, Madrid: Siglo XXI, 1983, pp. 1012; Carolyn P. BOYD: Praetorian..., op. cit., p. 29.

${ }^{18}$ Una colección de análisis excelentes sobre Alfonso XIII está en Javier MORENO LUZÓN (ed.), Alfonso XIII. Un político en el trono, Madrid, Marcial Pons, 2003. Ver también el artículo de Javier MORENO LUZÓN, "Los partidos gubernamentales y el rey, 1913-1923', Francisco J. ROMERO SALVADÓ y Angel SMITH (eds.), La agonía..., op. cit., pp. 33-36.
}

19 Melchor FERNÁNDEZ ALMAGRO, Historia del reinado de Alfonso XIII, Barcelona, Montaner \& Simón, 1977 [1933]), p. 38.

${ }^{20}$ Gabriel CARDONA, Alfonso XIII..., op. cit., pp. 71-74; Carolyn P. BOYD, “El Rey-Soldado”, Javier MORENO LUZÓN (ed.), Alfonso XIII..., op. cit., pp. 215-237.

${ }^{21}$ Una caricatura, aparecida el 23 de noviembre de 1905 en el ¡Cu-Cut! (un semanario satírico catalán), burlándose del ejército colmó la paciencia de la guarnición local. Esa noche unos 200 oficiales asaltaron los locales del semanario y luego hicieron lo mismo en la sede de La Veu de Catalunya, órgano de prensa de la Lliga. La actitud del rey fue decisiva pues substituyó al gobierno entonces presidido por Eugenio Monteros Ríos por uno encabezado por otro dirigente del Partido Liberal, Segismundo Moret, quien introdujo en marzo de 1906 la Ley de Jurisdicciones. Los oficiales no sólo no sufrieron sanción alguna sino que a partir de entonces la justicia militar adquiría potestad sobre ofensas de cualquier tipo (alegorías, símbolos, caricaturas, signos, etc.) a la corona, la patria o el ejército. Ver "relato de los sucesos y despachos militares", 26 de noviembre - 4 de diciembre de 1905, no. 5865-39, Sección de orden público, Archivo General Militar de Madrid. Véase también, Jordi CASASSAS YMBERT (ed.) Els fets del Cu-Cut!, cent anys després, Barcelona, Centre d'Història Contemporània de Catalunya, 2006.

HISPANIA NOVA., 15 (2017), págs. 416-442

DOI: https://doi.org/10.20318/hn.2017.3496 
El modelo español representaba la variante local del sistema hegemónico entonces en una Europa donde a pesar de la existencia de mecanismos constitucionales, las sociedades políticas y civiles estaban aun esencialmente dominadas por elementos del antiguo régimen: sus jefes de estado eran, en su inmensa mayoría, monarquías hereditarias que presidían vastas burocracias civiles y militares alimentadas en los principios de jerarquía social; las clases terratenientes conservaban una posición preminente en la corte, la diplomacia, la judicatura y las fuerzas armadas; las cámaras altas de sus parlamentos eran auténticos baluartes de un pasado feudal; una variedad de dispositivos (sufragios censitarios, clientelismo, desproporcionado peso del voto rural, etc.) garantizaban la persistencia de una elite gobernante, etc. ${ }^{22}$.

Según Arno Mayer, la Gran Guerra constituyó la expresión de la decadencia y caída de un antiguo orden que luchaba por prolongar su vida ${ }^{23}$. Ante el desafío de la modernidad, las elites gobernantes pensaban que una decisiva victoria tras una campaña militar relativamente breve era una fórmula válida para silenciar los crecientes movimientos de protesta socio-política. $Y$, efectivamente, las muestras de patriotismo fueron la tónica general en todos los rincones de Europa. Las resoluciones aprobadas congreso tras congreso por la II Internacional Socialista - Stuggart (1907), Copenhague (1910) y Basilea (1912) llamando a organizar una huelga general para impedir el cataclismo que produciría una guerra imperialista fueron ignoradas. La gran mayoría de los dirigentes de los partidos socialistas y centrales sindicales se sumaron al esfuerzo bélico, votaron los presupuestos de guerra y en países como Francia incluso Marcel Sembat y Jules Guesde materializaron esta union sacrée entrando en el gobierno como ministros de obras públicas y sin cartera respectivamente ${ }^{24}$. Una minoría socialista, horrorizada ante lo que percibían como traición de sus compañeros, comenzó a demandar la creación de una nueva internacional obrera.

En 1917, las tensiones del conflicto sacudieron los cimientos del orden socio-político que con sus imprevisiones y decisiones lo habían incubado ${ }^{25}$. Mientras la moderación obrera de los primeros años desembocaba en creciente militancia, la disciplina de las tropas comenzó a resquebrajarse. EI ejército francés se tambaleó en la primavera cuando 54 divisiones se amotinaron. Coincidiendo con un movimiento huelguístico que congregó a más de 300.000 obreros, el Partido Social-Demócrata Alemán, partidario de apoyar el esfuerzo bélico, se fracturó con la creación de un Partido Social-Demócrata Independiente en abril que contenía a la Liga Espartaquista (embrión del futuro Partido Comunista Alemán). El Imperio Austro-Húngaro comenzó a desmoronarse debido a su desintegración interna y la militancia obrera. En agosto, Italia experimentó motines de subsistencias que degeneraron en barricadas en Turín y una situación cercana al derrumbamiento tras la desastrosa derrota de Caporetto en octubre. Pero, el epicentro de la revolución se situó en Rusia.

\footnotetext{
22 Arno MAYER, La persistencia..., op. cit., pp. 15-25, 276-278; Julián CASANOVA, Europa contra Europa, 19141945, Barcelona, Crítica, 2011, pp. 8-9.

${ }^{23}$ Arno MAYER, La persistencia..., op. cit., p. 15.

${ }^{24}$ Donald SASSOON, One Hundred Years of Socialism, Londres, HarperCollins, 1996, pp. 27-29; Neil HARDING, Lenin's Political Thought, 2 Vols., Londres, Macmillan, 1983, Vol. 2, pp. 16-18; Carlos FORCADELL, Parlamentarismo..., op. cit., pp. 71-75.

${ }^{25}$ Arno MAYER, La persistencia..., op. cit., p. 15.
} 
En los albores de la Gran Guerra, Rusia seguía siendo un país eminentemente agrícola aunque tras una serie de reformas (incluyendo la abolición de la servidumbre en 1861) había comenzado un gigantesco programa de modernización saltando de golpe del estadio artesanal al de complejos industriales masivos en algunas ciudades. Pero, a pesar de ciertas concesiones constitucionales en 1905, era gobernada por una autocracia: el poder se hallaba concentrado en las manos del soberano (Zar) cuya autoridad se sustentaba en una vasta burocracia y fuerzas armadas cuyos cuadros dirigentes pertenecían principalmente a una aristocracia omnipotente. La innata intransigencia del régimen obligaba a su derrocamiento como premisa previa para alcanzar cualquier transformación socio-política significante.

La revolución pilló a los líderes socialistas por sorpresa. El mismo Vladimir llyich Ulyanov (Lenin), aislado en Suiza, concluyó en enero de 1917 que el zarismo estaba condenado pero su caída no la contemplaría su generación ${ }^{26}$. Sin embargo, la voluntad de derrocar a la autocracia estaba implantada en las masas obreras ${ }^{27}$. De hecho, como indica Orlando Figes, todo comenzó por la cuestión del pan ${ }^{28}$. Con motivo del Día Internacional de la Mujer (8 de marzo de 1917), obreras textiles marcharon en protesta contra la escasez de pan en la capital, Petrogrado ${ }^{29}$. Durante los siguientes días, la protesta inicial se transformó en una rebelión cuando prácticamente todo el proletariado de la capital abandonó sus puestos de trabajo y ocupó las calles con gritos contra el régimen zarista. Desbordados por los acontecimientos, el gobierno ordenó la intervención de la guarnición pero las tropas gradualmente comenzaron a fraternizar con los manifestantes. El 12 de Marzo, la capital se hallaba en manos de los revolucionarios. Tres días más tarde, los generales conminaban al Zar Nicolás II a abdicar. El triunfo de la revolución dio lugar a una situación peculiar de "poder dual". Por un lado, los revolucionarios, amos de la calle pero inseguros sobre cómo proceder, decidieron establecer organismos de democracia popular: soviets (consejos) de obreros, campesinos y soldados. Sin embargo, con la mayoría de sus dirigentes históricos en el exilio o en prisión, los Soviets permitieron la continuidad de la legalidad constitucional encarnada por un Gobierno Provisional formado por diputados del parlamento zarista. Solo un miembro del Soviet de Petrogrado, Aleksandr Kerensky, ocupó la cartera de justicia en el Gobierno Provisional simbolizando la colaboración entre los dos centros de poder ${ }^{30}$. El resultado fueron meses de inestabilidad hasta que el 7 de noviembre los Bolcheviques tomaron por la fuerza el poder ${ }^{31}$.

\footnotetext{
${ }^{26}$ Ronald G. SUNY, The Soviet Experiment: Russia, the USSR and the Successor States, Oxford, OUP, p. 35.

${ }^{27}$ Edward ACTON, Rethinking..., op. cit., pp. 117-118.

${ }^{28}$ Orlando FIGES, A People's Tragedy: The Russian Revolution, 1891-1924, Londres, Jonathan Cape, 1996, p. 307.

${ }^{29}$ Al estallar la guerra con Alemania en 1914 se rusificó el nombre de San Petersburgo que pasó a llamarse Petrogrado.

${ }^{30}$ En su fascinante relato de los hechos el Menchevique Nikolai N. Himmer (SUKHANOV) sugiere que Kerensky actuó por su cuenta contra los acuerdos del Comité Ejecutivo del Soviet y luego les presentó un hecho consumado: The Russian Revolution, 1917, Oxford, OUP, 1955, pp. 141-143.

${ }^{31}$ Con motivo del décimo aniversario de la captura del poder por los Bolcheviques, el reputado cineasta soviético realizó la película Octubre, cuyo foco central era la épica movilización de la población durante la toma del palacio de invierno, sede del Gobierno Provisional. En realidad, el Palacio cayó sin apenas resistencia mientras la ciudad proseguía con su vida diaria. Sólo dos personas perdieron su vida a diferencia de las 1.330 víctimas de la revolución de marzo. La literatura sobre el ciclo revolucionario ruso de 1917 es colosal. Hay 5.896 títulos reseñados en la espléndida colección bibliográfica producida por el profesor de estudios soviéticos en Queen Mary
} 
En 1917, el fenómeno insurreccional ruso parecía el cenit del esplendor revolucionario que parecía cernirse sobre Europa. Lenin pensaba que era el prólogo de un proceso que culminaría con el triunfo del socialismo a nivel mundial ${ }^{32}$. La experiencia del más oprimido pueblo derribando al régimen más despótico seguramente podía repetirse en otros lugares.

\section{EL VERANO CALIENTE DE 1917}

Desde la tierra de los zares a la península ibérica, fuertes vientos de cambio amenazaron con arrastrar a su paso a sus cuestionados dirigentes. La movilización de sectores de la sociedad española contra el orden socio-político imperante alcanzó un momento crítico en 1917. Sin embargo, esta crisis también consolidó la autoridad de dos instituciones no necesariamente destacadas por sus inclinaciones liberales: fuerzas armadas y corona.

Siguiendo el esquema de Soldevilla y Lacomba, la primera fase del ciclo revolucionario fue protagonizada por el reto pretoriano. La convulsión económica producida por la guerra había afectado el hasta entonces relativamente estable nivel de vida del funcionariado tanto civil como militar. Su respuesta fue recurrir a soluciones corporativas: la creación de juntas en la práctica totalidad de la administración pública para defenderse contra el creciente deterioro de su capacidad adquisitiva ${ }^{33}$. En el caso de las fuerzas armadas, sus miembros no sólo experimentaron una importante merma de su poder adquisitivo sino que además contemplaban con ansiedad, debido a su pobreza técnica, la posibilidad de verse arrastrados hacia la guerra. Las alarmas se dispararon al introducirse una serie de reformas en 1915 y 1916 con el objetivo de reducir el hipertrofiado cuerpo por medio de pruebas de aptitud tanto físicas como intelectuales para poder invertir los subsiguientes ahorros en la modernización de los servicios y la adquisición de material bélico ${ }^{34}$. Consecuentemente, durante el año

College (Londres), Jonathan D. Smele, The Russian Revolution and Civil War, 1917-1921. An Annotated Bibliography, Londres, Continuum, 2003. Dentro de esta inmensa bibliografía, deben citarse: William H. CHAMBERLIN, The Russian Revolution, 1917-1921, 2 Vols., Princeton, Princeton University Press, 1987 [1935]); Stephen A. SMITH, Red Petrograd: Revolution in the Factories, Cambridge, CUP, 1983; Richard PIPES, The Russian Revolution, 1899-1919, Londres, HarperCollins, 1990; Edward ACTON, Rethinking the Russian Revolution, Londres, Arnold, 1990; Robert SERVICE, The Russian Revolution, 1900-1927, Londres, Macmillan, 1991; James D. WHITE, The Russian Revolution, 1917-1921, Londres, Arnold, 1994; Orlando FIGES, A People's..., op. cit.; Christopher READ, From Tsar to Soviets: The Russian People and their Revolution, 1917-21, Londres, UCL Press, 1996; Rex A. WADE, The Russian Revolution, 1917, Cambridge, CUP, 2005; Stephen A. SMITH, The Russian Revolution. A Very Short Introduction, Oxford: OUP, 2002; Abraham ASCHER, The Russian Revolution. A Beginner's Guide, Londres, Oneworld, 2014; y trabajos de Jonathan D. SMELE: Historical Dictionary of the Russian Civil Wars, 1916-1926, 2 Vols., Londres, Rowman \& Littlefield, 2015 y The Russian Civil..., op. cit. Entre las obras de los protagonistas debe incluirse: Leon TROTSKY, The History of the Russian Revolution, 3 Vols., Nueva York, Monad Press, 1980 [1918]; Victor CHERNOV, The Great Russian Revolution, New Haven, Yale University Press, 1936; SUKHANOV, The Russian..., op. cit.; Alexandr KERENSKY, Memoirs, Londres, Cassell \& Company Ltd, 1965; Pavel MILIUKOV, Political Memoirs, Arbor, University of Michigan Press, 1967; John REED, Ten Days..., op. cit.

\footnotetext{
32 Neil HARDING, Lenin's..., op. cit., Vol. 2, pp, 160-161.

${ }^{33}$ Francisco VILLACORTA BAÑOS, Profesionales y burócratas. Estado y poder corporativo en la España del Siglo XX, 1890-1923, Madrid, Siglo XXI, 1989, pp. 372-373.

${ }^{34}$ Ministro de la Guerra, General RAMÓN ECHAGUE, "decreto de reforma del estado mayor", 9 de noviembre de 1915, 15,614/6, Sección Reinado de Alfonso XIII, Archivo General del Palacio Real (AGPR). Carolyn P. BOYD, Praetorian..., op. cit., pp. 51-53.
}

HISPANIA NOVA., 15 (2017), págs. 416-442

DOI: https://doi.org/10.20318/hn.2017.3496 
1916, oficiales hasta el rango de coronel comenzaron a afiliarse en Juntas Militares de Defensa, una especie de sindicato castrense cuyo organismo central se hallaba en Barcelona. Su órgano de prensa, La Correspondencia Militar, adoptó un discurso reformista y crítico del régimen al que culpaba de favorecer los privilegios de una elite formada por los oficiales de la casa del rey o destinados en África donde el nepotismo reinante facilitaba la rápida adquisición de medallas y ascensos. Sin embargo, el objetivo primordial era la defensa de los intereses corporativos: mejores sueldos y condiciones y la imposición de la escala cerrada (promoción basada en antigüedad) ${ }^{35}$.

Aunque conscientes de su existencia, tanto el gobierno de Álvaro de Figueroa (Conde de Romanones) como el General Felipe Alfau, capitán general de Cataluña, decidieron inicialmente no intervenir. Sin embargo, el rey acabo ordenando en mayo de 1917 al ministro de Defensa, General Manuel Aguilera, la disolución de las Juntas ${ }^{36}$. Obsesionado con los acontecimientos en Rusia ${ }^{37}$, el monarca percibía erróneamente en aquellas una amenaza semejante al estado de insumisión que había llevado a la oficialidad zarista a desertar su soberano. Tal decisión tuvo drásticas consecuencias. Tras negarse a disolver su organización, los dirigentes junteros en Barcelona fueron arrestados. La indisciplina se convirtió en desafío cuando una junta provisional, creada inmediatamente por sus compañeros, publicó el 1 de junio un manifiesto que daba al gobierno un plazo de 12 horas para liberar a sus líderes en prisión, ofrecer garantías de no tomar represalias y reconocer oficialmente sus estatutos ${ }^{38}$. Era un auténtico ultimátum pues las diferentes juntas locales habían recibido instrucciones para proceder, en caso de una reacción de fuerza por parte del ejecutivo, a la ocupación de gobiernos militares y cuarteles generales $^{39}$. Desconcertado tras menos de dos meses en el poder, el gobierno de Manuel García Prieto (Marqués de Alhucemas) intentó ocultar la gravedad de la situación mientras buscaba una fórmula de compromiso. No fue posible pues en sus diarias editoriales tituladas "la cuestión militar", La Correspondencia Militar se jactaba que la rebelión juntera representaba "el prólogo de la dignificación de España y la sentencia a muerte del imperio del caciquismo y la oligarquía en todos los órdenes de la vida nacional". El 6 de junio, un diario cercano al Partido Liberal, El Heraldo de Madrid, titulaba su editorial, "En España ha comenzado la revolución". Cuatro días después, el gobierno presentaba su dimisión.

La sensación de vacío político pareció confirmarse cuando el rey, procediendo con el turno como si fuesen tiempos normales, llamó al poder a Eduardo Dato, líder del Partido Conservador. Simultáneamente, las juntas demandaban un nuevo tipo de política diferente a "la oligarquía gobernante que estaba conduciendo a la decadencia moral y la ruina económica del país" ${ }^{40}$. Pablo Iglesias, el cauto patriarca del

\footnotetext{
35 ibídem, pp. 54-59; José BUXADÉ, España..., op. cit., pp. 35-39; Benito MÁRQUEZ y José-María Capó, Las juntas militares de defensa, La Habana, Porvenir, 1923, pp. 23-25; Juan Antonio LACOMBA, La crisis..., op. cit., pp. 110115.

${ }^{36}$ ROMANONES, Notas de una vida, Madrid, Marcial Pons, 1999 [1929-1947], pp. 413-414; Fernando SOLDEVILLA, Tres revoluciones..., op. cit., pp. 50-53.

37 Una obsesión constatada por el embajador británico Arthur HARDINGE, "despacho a Balfour", 19 de mayo de 1917, 185-1344/268, Foreign Office Papers (FO), National Archives (NA).

${ }^{38}$ Benito MÁRQUEZ y José-María Capó, Las juntas..., op. cit., pp. 178-179.

39 Instrucciones para un golpe de estado están en capitán de artillería SALVADOR FURIOL, "carta a Antonio Maura, 5 de junio de 1917, 402/22, Archivo Antonio Maura (AAM), Fundación Antonio Maura.

40 “La nueva política”, La Correspondencia Militar, p. 1, 14 de junio de 1917.
} 
socialismo español, concluyó que se estaba asistiendo a un divorcio entre el régimen y su guardia pretoriana ${ }^{41}$. En medio de la confusión general y entusiasmo ante la aparente agonía del sistema gobernante, la Lliga Regionalista de Catalunya (Lliga) se erigió en el protagonista de una segunda fase reformista o parlamentaria.

Lejos de separatista o revolucionaria, la Lliga, fundada en 1901, era un partido de orden. Principal representante del catalanismo político, combinaba elementos reformistas con un nacionalismo pragmático. Defendía la idea de una Espanya Catalana: España solo podía recobrar su antigua gloria como una nación de naciones liderada por la más dinámica Cataluña. Percibiendo al estado como reticente a defender los intereses industriales de su región y ser un instrumento de las clases terratenientes del centro y sur de España, la Lliga quería reformar la monarquía y acabar con el monopolio de poder del turno dinástico ${ }^{42}$.

Ante las circunstancias especiales creadas por la guerra donde la demanda externa por su producción textil y metalúrgica había favorecido la expansión del peso económico de Cataluña ${ }^{43}$, la Lliga vio la oportunidad de llevar a cabo su ofensiva para reformar el estado. En el verano de 1916, consiguió pasar de ser una fuerza relativamente marginal a nivel nacional a ser el centro de una movilización contra un gobierno dinástico. Esta empresa fue facilitada por el intento del ministro de Hacienda, Santiago Alba, de introducir un ambicioso plan de reconstitución nacional financiado por medio de nueva tributación incluyendo un impuesto sobre los beneficios extraordinarios de la guerra conseguidos por la industria y el comercio, pero no la agricultura ${ }^{44}$. Los dirigentes catalanes encabezaron en las Cortes y en la calle una campaña que movilizó a las principales organizaciones empresariales del país (Fomento del Trabajo Nacional de Barcelona, Asociación de Navieros de Bilbao, Círculo de la Unión Mercantil e Industrial de Madrid, Cámara de Comercio de Zaragoza, Unión Gremial de Valencia, etc. $)^{45}$.

\footnotetext{
41 “El deber de las izquierdas ante la situación actual”, p. 1, 12 de junio de 1917.

42 Jesús PABÓN, Cambó, 1876-1947, Barcelona, Alpha, 1999 [1952-1958], p. 386; Charles E. EHRLICH, “Per Catalunya i I'Espanya Gran: Catalan Regionalism on the Offensive, 1911-1919", European History Quarterly, no. 28/2 (1998), pp. 190-191; Angel SMITH, "La Lliga Regionalista, la derecha catalana y el nacimiento de la dictadura de Primo de Rivera”, Francisco J. ROMERO SALVADÓ y Angel SMITH (eds.), La Agonía..., op. cit., pp. 142-143.
}

43 Carme Massana, Industria, ciutat $i$ proprietat, Barcelona, Curial, 1985, pp. 14-16. En 1920, Barcelona representaba 75 por ciento de toda la actividad textil en España, 36 por ciento de su industria de papel, 33 por ciento de su producción química, 25 por ciento de su metalurgia, etc.

${ }^{44}$ Mercedes CABRERA, Francisco COMín y José Luis GARCÍA DELGADO, Santiago Alba. Un programa de reforma económica del primer tercio del Siglo XX, Madrid, Instituto de Estudios Fiscales, 1989.

${ }^{45}$ Aparte de motivos económicos, existían razones coyunturales para torpedear los planes de Alba. El Partido Liberal poseía una historia de hostilidad hacia la Lliga. Destacado representante de esa tendencia, Santiago Alba, en el puesto de ministro de la Gobernación, había organizado una amplia coalición (Pacto de la Castellana) que incluía a partidos republicanos para derrotarla en las elecciones de abril de 1916. No obstante, la Lliga mejoró sus resultados previos e incluso cosechó un gran triunfo en Barcelona. Cuando poco después Alba pasó al ministerio de Hacienda, la Lliga no podía consentir un éxito que podía catapultarle a la jefatura de su partido. Ver Francesc CAMBÓ, "correspondencia con Enric Prat de la Riba", 9 de julio de 1916, Archivo Enric Prat de la Riba (AEPR), Arxiu Nacional de Catalunya (ANC); y Francesc CAMBÓ, Memorias, Madrid, Alianza, 1987, p. 227: “Nuestro propósito era llevar a Santiago Alba a un fracaso total, a fin de que el escarmiento fuera lo bastante notorio para que nadie más tuviera la tentación de hacer contra nosotros maniobras de cerco"; octubre-noviembre de 1916, Caja 3/2, nos. 1617, Institut Francesc Cambó; Francesc CAMBÓ, “correspondencia a Prat de la Riba", 5 de noviembre de 1916,

HISPANIA NOVA., 15 (2017), págs. 416-442

DOI: https://doi.org/10.20318/hn.2017.3496 
Las rivalidades e indisciplina de los partidos dinásticos colaboraron a su triunfo ${ }^{46}$. A fines de 1916 , el Partido Liberal estaba fracturado y Alba contemplaba el colapso de su programa económico y además fracasaba en aprobar el presupuesto anual ${ }^{47}$.

Animados por el desconcierto institucional producido por el desafío juntero, los dirigentes de la Lliga publicaron, el 15 de junio, un manifiesto alegando que la desobediencia militar imposibilitaba continuar con un régimen basado en la ficción electoral. Ante la actitud del gobierno, imposibilitando la discusión de la crisis a base de la suspensión de garantías constitucionales y unas Cortes cerradas, invitaron a todos los diputados catalanes a reunirse en el ayuntamiento de Barcelona el 5 de Julio; invitación luego extendida al resto de los diputados españoles a atender una asamblea en la ciudad condal el 19 de julio ${ }^{48}$. La iniciativa fue rápidamente apoyada por republicanos y socialistas. Atendida por 55 diputados y 13 senadores, la asamblea aprobó resoluciones de gran alcance, antes de ser disuelta por la policía: la denuncia de un régimen oligárquico, la elección de unas Cortes Constituyentes en unos comicios presididos por un gobierno que representase la voluntad nacional y la creación de tres comisiones para estudiar respectivamente la primera, la reforma constitucional que incluiría la autonomía para aquellas regiones que lo deseasen, la segunda, la defensa nacional, la enseñanza y la administración de justicia, y la tercera, los urgentes problemas socio-económicos ${ }^{49}$.

El 13 de agosto, el ciclo revolucionario alcanzó su fase más crítica con el estallido de una huelga general indefinida dirigida por los tradicionalmente prudentes dirigentes del movimiento socialista, en muchos casos los mismos en las ejecutivas del Partido Socialista Obrero Español (PSOE) y del sindicato Unión General de Trabajadores (UGT). Su decisión de embarcarse en un choque frontal con el estado habría sido algo impensable antes de la Gran Guerra.

La guerra contribuyó a agudizar las diferencias estructurales y sociales del país. La clase obrera fue la más drásticamente golpeada por un cóctel letal de opulencia y miseria ${ }^{50}$. La explosión en las exportaciones produjo beneficios extraordinarios para ciertos sectores mineros e industriales (textil, química, metalurgia, etc.). Empresas navieras, aventuras comerciales y entidades bancarias experimentaron un auge espectacular ${ }^{51}$. Metrópolis industriales como Barcelona entraron en una fase de actividad febril convirtiéndose en polo de atracción de mano de obra barata procedente de zonas rurales. Pero, la ostentación y despilfarro de las fortunas rápidamente adquiridas por barones

AEPR. Ver también Mercedes CABRERA, Francisco COMín y José Luis GARCíA DELGADO, Santiago Alba..., op. cit., pp. 375-406; Francisco J. ROMERO SALVADÓ, España..., op. cit., pp. 56-61.

${ }^{46}$ Según Francesc CAMBÓ (Memorias..., op. cit., p. 240), rivales de Alba en su partido incluyendo el mismo jefe de gobierno, Conde de Romanones, estaban encantados de ver la derrota de Alba.

47 13-14 de diciembre de 1916, 11/8903, Diarios de Natalio Rivas (DNR), Biblioteca de la Real Academia de la Historia (BRAH).

48 "Document trascendental. Els parlamentaris regionalistes al país", La Veu de Catalunya, p. 1, 15 de junio de 1917; Juan Antonio LACOMBA, La crisis..., op. cit., pp. 172-180.

49 "Juntas y Movimiento revolucionario de 1917 ", Archivo Eduardo Dato, BRAH. Véase también, Fernando SOLDEVILLA, El año político de 1917, Madrid, Julio Cosano, 1918, pp. 306-311; Luis SIMARRO, Los sucesos de agosto en el parlamento, Madrid, Tipografía artística, 1918, apéndice 2C, pp. 365-377.

${ }^{50}$ Francisco J. ROMERO SALVADÓ: Foundations..., op. cit., pp. 26-28.

${ }^{51}$ José Luis GARCÍA DELGADO, La modernización económica en la España de Alfonso XIII, Madrid, Espasa, 2002, pp. 107-124.

HISPANIA NOVA., 15 (2017), págs. 416-442

DOI: https://doi.org/10.20318/hn.2017.3496 
industriales, especuladores, magnates financieros y navieros contrastaban con la miseria de la mayoría. La demanda externa unida al descenso en picado de las importaciones disparó la inflación e incrementó el acaparamiento y la carestía de las subsistencias. Simultáneamente, la avalancha demográfica encareció el coste de los alquileres, impulsó el chabolismo y empeoró las ya miserables condiciones de las clases obreras $^{52}$.

Desde principios de 1916, la conflictividad social (huelgas, motines de subsistencias, asaltos a panaderías, etc.) comenzó a alcanzar niveles alarmantes de violencia. Para desazón de los trabajadores, pequeños aumentos salariales eran rápidamente eliminados por la inflación galopante y el cada vez más inaccesible precio de productos básicos (pan, huevos, azúcar, carne, etc. $)^{53}$. Las circunstancias críticas, la hemorragia de militantes ${ }^{54}$, la falta de iniciativas gubernamentales y la presión de sus bases, obligaron a los dirigentes socialistas a aceptar medidas extraordinarias. El punto de inflexión tuvo lugar durante el XII Congreso de la UGT (17 - 24 de mayo de 1916). En primer lugar, aprobó una moción pactada por la ejecutiva a iniciativa de uno de sus miembros, Daniel Anguiano, acordando el inicio de una campaña de educación del proletariado basado en manifestaciones y asambleas en toda España para forzar al gobierno y a las Cortes a introducir legislación para mitigar la crisis socio-económica. Y segundo, apoyó la apertura de negociaciones con el sindicato rival, la anarco-sindicalista Confederación Nacional del Trabajo (CNT), para conseguir la unidad proletaria, algo finalmente sellado en julio ${ }^{55}$. Aunque reacios a colaborar con los "alborotadores" anarquistas, los socialistas no podían ignorar las demandas de sus bases en favor de la unidad obrera ni el voto masivo por la moción en esas líneas presentada por la delegación asturiana. Además, creían poder controlar la agenda dada su mayor fuerza estatal: la UGT contaba con unos 80.000 militantes implantados por todo el territorio nacional mientras la CNT sólo contaba con unos 30.000 , su gran mayoría en Cataluña ${ }^{56}$.

\footnotetext{
52 INSTITUTO DE REFORMAS SOCIALES, Encarecimiento de la vida durante la Guerra. Precios de las subsistencias en España y en el extranjero, 1914-1918, Madrid, Sobrinos de la Sociedad de M. Minuesa, 1918; Chris EALHAM, Class, Culture and Conflict in Barcelona, 1898-1937, London, Routledge, 2005, pp. 6-9.

53 INSTITUTO DE REFORMAS SOCIALES, Movimientos de precios al por menor en España durante la guerra y la posguerra, Madrid, Sobrinos de la Sociedad de M. Minuesa, 1923, pp. 10-11, 36: Con una base 100 para 1914, los salarios de hombres y mujeres se habían incrementado en 1918 a 125'6 y 125'1 respectivamente, pero el índice de precios había ascendido a 175'6 (campo) y 164'7 (ciudades).

${ }^{54}$ El número de afiliados de la UGT descendió de 147.729 (enero de 1913) a 76.304 (enero de 1916).

55 "El proletariado emplaza al gobierno", El Socialista, p. 1, 24 de mayo de 1916. "Demandas de la militancia y discusiones de la ejecutiva socialista", enero-mayo de 1916, Archivo Amaro del Rosal, Actas del Comité Ejecutivo de la UGT, 1916-1918 (AARD-IX), Fundación Pablo Iglesias (FPI). Un análisis del congreso en Francisco J. ROMERO SALVADÓ, The Foundations..., op. cit., pp. 31-34.

${ }^{56}$ Entre otras organizaciones, los sindicatos de albañiles y marmolistas de Madrid habían pedido negociaciones con la CNT, mayo de 1916, AARD-IX. Según el miembro del comité ejecutivo de la UGT, Andrés Saborit, los delegados asturianos, Isidoro Acevedo y Manuel Llaneza eran, como los líderes nacionales, reacios a una alianza con la CNT pero se vieron obligados a introducir la moción votada por los mineros asturianos que ellos representaban: 19151917, pp. 1963-1964, Archivo de Andrés Saborit Colomer, FPI. Ver también, Paul HEYWOOD, Marxism and the Failure of Organized Socialism in Spain, 1879-1936, Cambridge, CUP, 1990, pp. 40-41.
}

HISPANIA NOVA., 15 (2017), págs. 416-442

DOI: https://doi.org/10.20318/hn.2017.3496 
El movimiento libertario, tras haber sido la fuerza obrera hegemónica en España y buena parte de Europa hasta la última década del Siglo XIX ${ }^{57}$ había entrado en un periodo de decadencia cuando las actividades de una minoría partidaria del terror (la llamada "propaganda por el hecho") facilitó a las autoridades la puesta en marcha de medidas destinadas a su represión ${ }^{58}$. En Cataluña, el gran baluarte del anarco-sindicalismo español, el círculo vicioso de terrorismo ácrata y brutalidad policial entre 1893 y 1897, seguido del rotundo fracaso de la huelga general de 1902, había sumido al movimiento libertario en crisis. Su nueva organización (CNT) había durado menos de un año desde su congreso fundacional hasta su ilegalización en septiembre de 1911. Tras el estallido de las hostilidades, aunque no sin relevantes excepciones de líderes históricos en favor de los Aliados (como el manifiesto de los 16 suscrito por el francés Jean Grave y el ruso Pyotr Kropotkin en marzo de 1916), el anarquismo internacional presentaba mucho menos fisuras que el marxismo en cuanto a su defensa a ultranza de la doctrina internacionalista clásica de condena a la guerra imperialista ${ }^{59}$. En Octubre de 1915, un congreso internacional significativamente llamado por la Paz, se celebró en El Ferrol. Dadas las dificultades obvias de desplazamiento, el congreso fue un fracaso en término de ausencia de delegados extranjeros. El congreso concluyó con el lema "la revolución antes que la guerra" y decidió la reconstrucción de la CNT. ${ }^{60}$ En mayo de 1916, coincidiendo con el congreso de la UGT, la CNT celebró una asamblea en Valencia que aprobó la propuesta de iniciar negociaciones con sus rivales socialistas ${ }^{61}$.

Los cenetistas recibieron la noticia del pacto obrero como la señal de que la revolución era inminente. Según uno de sus más carismáticos líderes, Ángel Pestaña, "se volcaron las cajas de los fondos de los sindicatos, entregando hasta el último céntimo para comprar pistolas y fabricar bombas.

\footnotetext{
${ }^{57}$ Las dos primeras centrales sindicales en España, la Federación Regional Española (1870-1881) y su sucesora la Federación de los Trabajadores de la Región Española (1881- 1888), se alienaron con las tesis anarquistas. Antes de la CNT, la Federación de Sociedades de Resistencia de la Región Española, fundada en 1900, fue el último intento de crear una organización anarco-sindicalista de masas pero acabó despareciendo en 1906 tras una serie casi ininterrumpida de derrotas.

${ }^{58}$ El concepto de 'propaganda por el hecho' empezó a ganar fuerza sobre todo entre militantes italianos en la década de 1870. Su énfasis radicaba en la idea que los actos insurreccionales eran la propaganda más efectiva para movilizar las masas. En aquel momento, tal consigna tenía un carácter teórico y a nivel de rebelión colectiva. Sin embargo, su interpretación comenzó a adquirir las connotaciones de un eufemismo para referirse a los atentados individuales durante los siguientes años. En julio de 1881, el congreso anarquista celebrado en Londres, sin duda bajo el impacto del reciente asesinato del Zar Alejandro II, se identificó plenamente con la estrategia de la 'propaganda por el hecho' e incluso introdujo en sus conclusiones la recomendación a los militantes de prestar gran atención a las ciencias químicas y técnicas, clara alusión al interés en la fabricación de explosivos. Ver Pier Carlo MASINI, Storia degli anarchici italiani da Bakunin a Malatesta, Milán, Rizzoli, 1969, p. 108; Caroline CAHM, Kropotkin and the Rise of Revolutionary Anarchism, Cambridge, CUP, 2002, pp. 86-87; Ze'ev IVIANSKY, 'Individual Terror: Concept and Tipology', Journal of Contemporary History, 12 (1977), p. 47; Juan AVILÉS, "Un punto de inflexión en la historia del anarquismo: El congreso revolucionario de Londres de 1881", Cuadernos de Historia Contemporánea, Vol. 34 (2012), pp. 159-180.

${ }^{59}$ Carlos FORCADELL, Parlamentarismo..., op. cit., 215-218.

60 Ibídem, p. 219.

61 "Petición de la asamblea anarco-sindicalista en Valencia a la comisión ejecutiva de la UGT para iniciar negociaciones sobre su unidad de acción", 11 de mayo de 1916, AARD-IX. Ver también Ángeles BARRIOS ALONSO, Anarquismo y Anarcosindicalismo en Asturias, 1890-1936, Madrid, Siglo XXI, 1988, p. 140.
}

HISPANIA NOVA., 15 (2017), págs. 416-442

DOI: https://doi.org/10.20318/hn.2017.3496 
Una fiebre de actividad invadió los medios confederales" ${ }^{\prime 2}$. Sin embargo, los socialistas distaban mucho de estar tramando una insurrección. Por ello, durante varias reuniones en el otoño de 1916, se vieron obligados a frenar a sus más impetuosos compañeros anarco-sindicalistas ${ }^{63}$. No obstante, a pesar de su prudencia, los socialistas habían suscrito una iniciativa que poseía un inmenso potencial revolucionario. El movimiento obrero español estaba más unido que nunca y crucialmente, por primera vez durante la Restauración, su marco de apuesta trascendía la habitual disputa sectorial o local. Además, la falta de respuesta del estado sólo podía endurecer la movilización obrera, como lo demostró el paro nacional de un día celebrado el 18 de diciembre de 1916. El 12 de enero de 1917, Pablo Iglesias se preguntaba en EI Socialista si el rey había buscado en un asilo mental a sus pacientes más graves para dirigir al país. Entusiasmados por los acontecimientos rusos, representantes de la UGT y la CNT firmaron en marzo un manifiesto responsabilizando al régimen de la miseria nacional y anunciando preparaciones para derribarlo por medio de una huelga general cuando las condiciones fueran favorables ${ }^{64}$. La insubordinación militar y de la asamblea les llevó a concluir en el verano de 1917 que aquellas se daban $\mathrm{y}$, por consiguiente, como en el caso de la autocracia zarista, el régimen caería como un castillo de naipes. No podían estar más equivocados. Tras cerca de una semana de sangrientos disturbios, las tropas habían aplastado la huelga revolucionaria en todo el país con la excepción de Asturias ${ }^{65}$.

\section{EL ARTE DE LA REVOLUCIÓN}

A finales de septiembre de 1917, Lenin escribió al comité central de su partido justificando la necesidad de tomar el poder por la fuerza. Tras rechazar tajantemente defender una variante de "Blanquismo" ${ }^{66}$, el veterano revolucionario insistió que la insurrección para ser un arte no debe consistir en una mera conjura sino aguardar a que se den las condiciones objetivas para su triunfo: una mayoría de los trabajadores han adquirido conciencia de clase y, por tanto, comprenden que la revolución es necesaria y están dispuestos a sacrificar su vida por ella y, al mismo tiempo, las clases dirigentes se encuentran en crisis divididas por sus vacilaciones. Dándose estas condiciones en ese momento en Rusia, negarse a tratar la insurrección como un arte equivalía a traicionar el marxismo y la

\footnotetext{
62 Ángel PESTAÑA, Lo que aprendí en la vida, 2 Vols., Murcia, Zero, 1971 [1933]), Vol. 1, p. 59.

63 "Reuniones del comité ejecutivo de la UGT con delegados no socialistas de otras regiones", 19, 26 de octubre, 2, 16 y 19 de noviembre de 1916, AARD-IX. Los dirigentes de la UGT rechazaron las demandas del secretario general de la CNT, Francisco Jordán, y dos anarquistas, Gabriel Calleja y José Villanova (representando respectivamente a la federación local de sindicatos obreros de Zaragoza y del sindicato de obreros textiles de Barcelona) en favor de una huelga general indefinida.

64 “El proletariado ante la nación”, El Socialista, p. 1, 28 de marzo de 1917.

65 Juan Antonio LACOMBA, La crisis..., op. cit., pp. 252-274; José BUXADÉ, La bullanga..., op. cit., pp. 251-296; Fernando SOLDEVILLA, El año..., op. cit., pp. 370-409; Francisco J. ROMERO SALVADÓ, España..., op. cit., pp.142157; Joan SERRALLONGA, "Motines..., op. cit.”, pp. 183-185; Mauro BAJATIERRA, Desde las barricadas..., op. cit., pp. 57-91.

66 "Blanquismo" o la corriente surgida alrededor de Louis Auguste Blanqui (1805-1881), el revolucionario francés quien consagró su vida a la causa de la revuelta armada y cuya actividad conspirativa sería acusada de aventurerismo por sus coetáneos socialistas.
}

HISPANIA NOVA., 15 (2017), págs. 416-442

DOI: https://doi.org/10.20318/hn.2017.3496 
revolución ${ }^{67}$. Mientras las tesis de Lenin fueron reivindicadas, el desenlace fue muy diferente en España donde las condiciones históricas para consumar el ciclo revolucionario nunca existieron.

Ningún experto sobre la revolución rusa difiere con Trotsky que la guerra produjo temporalmente las circunstancias que facilitaron su triunfo ${ }^{68}$. El cataclismo bélico destruyó la estructura tradicional socio-económica que sostenía al régimen zarista, dividió a su clase gobernante y pulverizó la lealtad de las fuerzas armadas.

Ya en 1905 , en vez de la "breve y triunfante guerra" en que soñaban los gobernantes ${ }^{69}$, la derrota en una disputa con Japón sobre ambiciones rivales en Manchuria había estimulado la oposición contra el ahora humillado régimen. La monarquía se tambaleó ante las manifestaciones de estudiantes, huelgas obreras masivas que culminaron con la creación de Soviets (Consejos) en San Petersburgo y Moscú, levantamientos campesinos, insurrecciones en provincias no rusas como Finlandia y Polonia, y motines en la flota ${ }^{70}$. El ciclo revolucionario sólo comenzó a abatir tras la concesión del Zar Nicolás II en octubre de una constitución ratificando los derechos civiles básicos, la legalización de partidos políticos y el establecimiento de un parlamento (Duma) elegido en voto libre ${ }^{71}$. Sin embargo, con el brote revolucionario bajo control en 1906, el zar, arrepentido de su reciente debilidad, reafirmó su control sobre el ejecutivo, política exterior, Iglesia y fuerzas armadas. La Duma fue disuelta tres veces entre 1906 y 1912 y el voto restringido para conseguir un parlamento cada vez más dócil ${ }^{72}$.

Si la experiencia de una pequeña y distante guerra había revelado la vulnerabilidad del hasta entonces impregnable zarismo, un cataclismo de la magnitud de la Gran Guerra consumó su destrucción. Las titánicas demandas del esfuerzo bélico quebró la fábrica estructural de la sociedad rusa. Cerca de 15 millones, en su mayoría campesinos, fueron enlistados dejando al campo desprovisto de mano de obra, ganado y materias primas; tres millones de soldados murieron o desaparecieron en

${ }^{67}$ Vladmir I. LENIN, "Marxism and Insurrection. A Letter to the Central Committee of the RSDLP (B)" (26-27 de septiembre de 1917), Lenin's Selected Works, Londres, Lawrence \& Wishart, 1971, pp. 357-361.

${ }^{68}$ Leon Trotsky, The Lessons of October, Londres, Bookmarks, 1985 [1924], p. 21.

${ }^{69}$ Palabras atribuidas al ministro del interior Vyacheslav K. von Plehve. Citado en William H. CHAMBERLIN, The Russian..., op. cit., Vol. 1, p. 47.

${ }^{70}$ Fundado el 13 de octubre de 1905, el Soviet de San Petersburgo cimentó la fama de su líder, Leon Trotsky, tras el arresto de su primer presidente (Georgii Stepanovich Nosar-Khrustalev) el 26 de noviembre sobre todotras la publicación de una obra sobre los acontecimientos: La Revolución de 1905, Barcelona, Planeta, 1975 [1907]). El motín del acorazado Potemkin, en junio, inmortalizado en el cine por Sérgei Eisenstein (1925) representó el punto culminante de la revuelta en la armada rusa. El momento más recordado es, sin embargo, el llamado domingo sangriento (22 de enero de 1905): la brutal disolución a balazos de la manifestación masiva pero pacífica, incluso portaba iconos religiosos y estandartes monárquicos, en camino hacia el Palacio de Invierno del zar en San Petersburgo para hacer entrega al monarca de sus demandas. Este episodio desvaneció la imagen del zar como el "padrecito del pueblo".

${ }^{71}$ Jonathan SMELE y Anthony HEYWOOD (eds.), The Russian Revolution of 1905. Centenary Perspectives, Londres, Routledge, 2005. El estudio más completo es Abraham ASCHER, The Revolution of 1905, 2 Vols., Stanford, Stanford University Press, 1988-1992.

72 Entrada del zar en su diario (1 de noviembre de 1905) lamentando su terrible decisión de hacer concesiones tomada bajo la presión de sus ministros y dando a entender que la revocaría tan pronto como desapareciese el peligro revolucionario, en Roger PETHYBRIDGE, Witnesses to the Russian Revolution, Londres, George Allen \& Unwyn, p. 45.

HISPANIA NOVA., 15 (2017), págs. 416-442

DOI: https://doi.org/10.20318/hn.2017.3496 
combate; espectaculares ofensivas se saldaron en amargas retiradas; las ciudades se vieron saturadas de refugiados y desabastecidas de fuel y productos básicos. Simultáneamente, la guerra quebrantó la unidad de la clase gobernante. Como indicó Trotsky, Rusia sufrió la misma crisis que el ancien régime francés $^{73}$ : un débil soberano, criado bajo la sombra de un poderoso padre, abrumado por la responsabilidad de un cargo basado en sus heredados derechos divinos, y dominado por una impopular reina extranjera, a su vez rodeada de una camarilla de aventureros como Grigori Efimovich Novoyk (Rasputín), un sórdido monje quien a pesar de su escandalosa vida se había ganado la confianza de la zarina pues parecía capaz de aliviar la hemofilia que devastaba la vida de su hijo y heredero ${ }^{74}$. Su asesinato por dos miembros de la aristocracia en diciembre de 1916 llegó demasiado tarde: el régimen se había convertido en objeto de escarnio y había sido abandonado por muchos de sus antiguos leales súbditos. Por ejemplo, dirigentes monárquicos como el empresario Alexandr Guchkov y el terrateniente Mikhail Rodzianko, antiguo y actual presidente de la Duma respectivamente, desde finales de 1915 formaron parte del "Bloque Progresivo" cuyo protagonista principal era el Partido Democrático Constitucional (Kadete), principal representante de las clases medias urbanas liberales cuyo objetivo era una reforma constitucional y la formación de un gobierno responsable ante el parlamento ${ }^{75}$. En 1916, el Bloque, habiéndose atraído a su órbita a numerosos generales, conspiraba contra el zar y su detestada mujer para remplazarlos por una monarquía constitucional sostenida por la Duma que prosiguiese la guerra sin obstáculos palaciegos ${ }^{76}$.

Tras la apocalíptica experiencia de casi tres años de combates, la cohesión y moral de las fuerzas rusas estaban gravemente quebrantadas. Un árbitro fundamental en el desenlace de los hechos fue la guarnición de Petrogrado, 150.000 jóvenes y díscolos reservistas hacinados en insalubres barracones previstos para 20.000 hombres, al solidarizarse con los revolucionarios tanto en marzo como en noviembre ${ }^{77}$. No solo las tropas desertaron al régimen, los generales también abandonaron al zar y aconsejaron su abdicación ${ }^{78}$. Hartos de la ineficiencia de la camarilla imperial, pensaban al principio que un cambio en el ocupante del trono era un precio razonable para proseguir con éxito la guerra. La revolución era percibida como un golpe de timón controlado por los respetables líderes monárquicos ahora en el Gobierno Provisional ${ }^{79}$. No habían anticipado que el derrumbamiento de la autocracia iba a desencadenar una tempestad. El Soviet de Petrogrado inmediatamente liquidaba toda

\footnotetext{
${ }^{73}$ Leon TROTSKY, The History..., op. cit., Vol. 1, pp. 75-77, 91-100.

${ }^{74}$ Edvard RADZINSKY, Rasputin: The Last Word, Londres, Weidenfled \& Nicolson, 2000.

75 Jonathan D. SMELE, Historical..., op. cit., Vol. 1, pp. 530-532.

${ }^{76}$ Leon TROTSKY, The History..., op. cit., Vol. 1, pp. 69-74.

${ }^{77}$ Christopher READ, From Tsar...op. cit., pp. 121-122. El momento clave fue la noche del tercer día de disturbios (11 marzo). Tropas del Regimiento Volynsky que habían destacado por su violencia ametrallando a los manifestantes, se amotinaron y mandaron emisarios a los barracones de otros regimientos. Por la mañana, la mayoría de la guarnición de Petrogrado había desertado a las autoridades.

78 Orlando FIGES (People's..., op. cit., pp. 341-342) sugieren que la revolución podía haber quedado confinada a Petrogrado y luego aplastada por tropas leales. Pero, el estado mayor zarista dirigido por el General Alexeev abandonó al zar quien acabó abdicando a favor de su hermano Miguel. La tesis del golpe palaciego llevado a cabo por el generalato es suscrita por Trotsky, The History, Vol. 1, pp. 87-9.
}

${ }^{79}$ David S. ANIN, “The February... op. cit.”, p. 447. 
ilusión de mantener la monarquía e introducía la llamada "Orden Número Uno" que anulaba el antiguo código de disciplina militar y sancionaba la creación de comités en los regimientos ${ }^{80}$

La revolución dejó el poder en manos de un Gobierno Provisional dominado por elementos del "Bloque Progresivo", es decir diputados monárquicos opuestos al radicalismo callejero que la había hecho posible. Su estrategia de subordinar cualquier tipo de reforma sustancial a la conclusión de la impopular guerra fue un error mayúsculo. A principios de mayo, el gobierno sufrió su primera grave crisis tras la filtración de que su principal miembro, el ministro de Asuntos Exteriores y líder del Partido Kadete, Pavel Nikolaevich Miliukov, había asegurado a los Aliados continuar la guerra a cambio de participar en el reparto imperialista tras la victoria ${ }^{81}$. La solución in extremis fue la dimisión del ministro y la constitución de un nuevo gobierno que incluía a seis miembros del Soviet. El nuevo hombre fuerte y encarnación de la nueva Union Sacrée producida por la revolución, era Kerensky, ministro de la Guerra y, desde el 21 de Julio, primer ministro ${ }^{82}$. Pero, tierra y paz eran los objetivos del ahora liberado soldado-campesino. Al apostar por una nueva ofensiva en julio, Kerensky quiso convertir la campaña en una guerra nacional-democrática que devolvería disciplina al ejército y consolidaría el nuevo régimen ${ }^{83}$. La consiguiente debacle arruinó su meteórico ascenso y el crédito del Gobierno Provisional y sus aliados en el Soviet. Nada en tal escala de derrumbamiento interno aconteció en España. El país se salvó de la terrible sangría humana y desgaste material que habría supuesto la participación en la guerra. Como reconocía Eduardo Dato, jefe del gobierno en el momento del estallido de las hostilidades, la neutralidad meramente reflejaba la realidad nacional: debilidad económica, incapacidad militar y marginalidad en el concierto europeo ${ }^{84}$. Sin embargo, como hemos visto, no pudo aislar España de su impacto. La convulsión socio-económica impulsó la movilización del regionalismo catalán, el movimiento obrero y la oficialidad castrense. No era la primera vez que sus reivindicaciones chocaban con gobiernos de la Restauración. La novedad consistía en que ahora coincidían cronológicamente y, además, estaban dispuestos a presentar un desafío frontal al estado.

La neutralidad fue mantenida a capa y espada hasta el final. De hecho, su defensa sería uno de los instrumentos usados por el Ministerio Dato para desbaratar la amenaza revolucionaria en 1917. Sin embargo, a medida que se prolongaba la contienda, el consenso inicial dio lugar a un proceso de polarización sin precedentes de la opinión pública que según Maximiliano Fuente Codera, lejos de limitarse a ciertas elites culturales y políticas, permeó a todas las capas de la sociedad ${ }^{85}$. Gerald Meaker sugiere que exacerbó la profunda división social existente y alcanzó el nivel de una guerra civil dialéctica

\footnotetext{
${ }^{80}$ SUKHANOV, The Russian..., op. cit., pp. 152-154.

${ }^{81}$ ibídem, The Russian..., op. cit., pp. 53-54.

82 David S. ANIN, “The February Revolution: Was the Collapse Inevitable?”, Soviet Studies, Vol. 18/4 (1967), p. 441.

${ }^{83}$ Según SUKHANOV (The Russian..., op. cit., p. 242), el dirigente Menchevique Iraki Tsereteli (miembro del comité ejecutivo del Soviet de Petrogrado y ministro de comunicaciones en el Gobierno Provisional) jugó un papel fundamental en vender la guerra como una campaña en defensa de la revolución.

${ }^{84}$ Gabriel MAURA y Melchor FERNÁNDEZ ALMAGRO: Por qué cayó Alfonso XIII, Madrid, Ambos Mundos, 1948, pp. $472-473$.

${ }^{85}$ Maximiliano FUENTES CODERA: España..., op. cit., p. 35.
} 
entre dos visiones contrapuestas sobre el futuro de España ${ }^{86}$. Fuera de los partidos dinásticos que se adhirieron abiertamente a la neutralidad oficial salvo, como veremos enseguida, el Conde de Romanones, no sin ciertas excepciones, los sectores e instituciones conservadoras (terratenientes, oficiales del ejército, Iglesia y corte) eran germanófilos pues identificaban a los Imperios Centrales con los principios y valores (tradición, autoridad y jerarquía social) que querían ver consolidados en España. Por el contrario, las profesiones liberales, los intelectuales, los republicanos y los socialistas, apoyaban a los Aliados, en particular Francia, asociados con el modelo de sociedad democrática y secular que deseaban ${ }^{87}$. La polarización ideológica fue exacerbada por la intrusión de los países beligerantes en la vida nacional, convirtiendo a España en el proceso, en un teatro indirecto de sus operaciones. Por ejemplo, Alemania creó una sofistica red de inteligencia en las principales ciudades y cerca de las costas para dirigir la campaña submarina contra buques mercantes y sabotear las fábricas cuya producción se exportaba a los Aliados y utilizaron el Marruecos español para fomentar la insurrección en el territorio bajo control francés ${ }^{88}$. Simultáneamente, el precio exorbitante del papel hizo posible el control extranjero de gran número de publicaciones. De este modo, la prensa se limitaba a difundir propaganda de quien la financiaba, fomentando con sus apocalípticas editoriales las ya enconadas pasiones ${ }^{89}$.

La polarización en torno a la neutralidad fue el detonante del ciclo revolucionario de 1917. La caída del Ministerio Romanones en abril de 1917 fue su punto de inflexión. El 19 de agosto de 1914, Romanones, entonces líder de la oposición dinástica, había conmocionado al país con la publicación de un artículo en su órgano de prensa, El Diario Universal, titulado "Neutralidades que matan" que rompiendo con la neutralidad oficial del estado abogaba, como indica Javier Moreno, más por motivos pragmáticos y económicos que ideológicos, el posicionamiento de España en la órbita de los Aliados: sus socios naturales. Ante la recepción negativa, Romanones rápidamente trató de rectificar por medio de un nuevo artículo donde matizaba su inquebrantable adhesión a la neutralidad ${ }^{90}$ Tras su regreso al poder en diciembre de

${ }^{86}$ Gerald MEAKER, "A Civil War of Words", Hans A. SCHMITT (ed.), Neutral Europe between War and Revolution, 1917-1923, Charlottesville, University of Virginia Press, 1988, p. 2.

87 ibídem, pp. 1-37; Fernando DÍAZ PLAJA, Francófilos y Germanófilos, Barcelona, Dopesa, 1973, pp. 24-25; Jesús LONGARES ALONSO: "Germanófilos y aliadófilos españoles en la Primera Guerra Mundial", Tiempo de Historia, 21 (1976); pp. 42-45; Maximiliano FUENTES CODERA: España..., op. cit., pp. 47-49; Francisco J. ROMERO SALVADÓ, España..., op. cit., pp. 11- 20; DEPARTAMENTO DE INTELIGENCIA, “Informe secreto", 17 de abril de 1916, 3712471/73.963, FO.

${ }^{88}$ Dos libros fundamentales son Eduardo GONZÁLEZ CALLEJA y Paul AUBERT: Nidos..., op. cit., y Fernando GARCíA SANZ: España..., op. cit. Un resumen de estas actividades está en "Acciones alemanas contra la neutralidad", 19 de abril de 1919, Archivo del Conde de Romanones (ACR), BRAH; e "Informe secreto", DEPARTAMENTO DE INTELIGENCIA, 23 de diciembre de 1916, 371-2762/260.662, FO, Ver también las secciones en este dossier de Anne ROSENBUSCH, Lola ELIZALDE y Pablo LA PORTE.

89 Javier PONCE MARRERO, "Propaganda and Politics: Germany and Spanish Opinion in World War I", Troy R. E. PADOCK (ed.), World War I and Propaganda, Leiden-Boston, Brill, 2014, pp. 293-321; Eduardo GONZÁLEZ CALLEJA y Paul AUBERT, Nidos..., op. cit., pp. 229-265; Francisco J. ROMERO SALVADÓ, España..., op. cit., pp. 79-81; “Informe secreto", DEPARTAMENTO DE INTELIGENCIA, octubre de 1917, 395-117/23798, FO.

90 Javier Moreno Luzón, Romanones. Caciquismo y política liberal (Madrid: Alianza, 1998), p. 309. Según ROMANONES (Notas de una vida, Madrid, Marcial Pons, 1999 [1929-1947\}, p. 379.) lo escribió mientras disfrutaba de su pasatiempo favorito, la caza de codornices. .). "El Problema de la neutralidad", El Imparcial, p. 1, 4 de septiembre de 1914: neutralidad no debía significar indiferencia pero cualquier ánimo belicoso equivaldría a perder la razón.

HISPANIA NOVA., 15 (2017), págs. 416-442

DOI: https://doi.org/10.20318/hn.2017.3496 
1915, el conde prosiguió la labor de acercamiento a la Entente y, en el proceso, incurrió en la ira de Alemania y de sus aliados en España que desde finales de 1916 iniciaron una campaña brutal para arrojarle del poder $^{91}$. El desprecio insultante de Alemania con sus constantes actividades subversivas hacia la neutralidad española seguido por el anuncio de la intensificación de su actividad submarina, desde el 1 de febrero de 1917, persuadieron al conde a emular el ejemplo de países hasta entonces neutrales como los Estados Unidos y varias repúblicas latino americanas. El embajador en París, Fernando León Castillo, recibió instrucciones para iniciar negociaciones con sus anfitriones ${ }^{92}$. El momento decisivo llegó con el hundimiento, el 5 de abril de 1917, del vapor San Fulgencio, torpedeado de vuelta a España con una vital carga de carbón galés tras haber llevado a Newcastle fruta portando un salvoconducto ${ }^{93}$. Para entonces Alemania ya había destruido 31 buques españoles ${ }^{94}$. Romanones confió al embajador francés, Leon Geoffray, que el momento había llegado para abandonar la neutralidad, sino "España se hundiría al nivel de potencia irrelevante como Holanda" ${ }^{95}$. Sin embargo, el 19 de abril se anunció su dimisión. Romanones no contaba con el apoyo ni siquiera de una mayoría en su partido (el nuevo gobierno, encabezado por un barón del Partido Liberal, el Marqués de Alhucemas, incluía a la mitad de los previos ministros) y mucho menos del estado mayor. Pero fundamentalmente, su dimisión fue provocada por la retirada de confianza de Alfonso XIII.

Inicialmente, el monarca parecía favorable a los Aliados $^{96}$. Romanones incluso escribió que se identificaba completamente con el espíritu de la letra de su editorial Neutralidades que matan ${ }^{97}$. Ambos veían en la guerra una oportunidad para ganar prestigio internacional y obtener concesiones territoriales. Dada la realidad militar y económica, el rey depositó sus esperanzas en presidir una mediación. España y su monarca hicieron méritos para ello representando los intereses de los países

91 “La injerencia extraña y la dignidad nacional”, El País, p. 1, 9 de enero de 1917. Francisco J. ROMERO SALVADÓ, "Fatal Neutrality: Pragmatism or Capitulation? Spain's Foreign Policy during the Great War", European History Quarterly, 33 (2003), pp. 292-315; José Luis MARTíNEZ SANZ: "El enfrentamiento Romanones-Ratibor", Hispania, 154 (1983), pp. 414-416.

92. Los Estados Unidos rompieron relaciones diplomáticas el 3 de febrero de 1917 y entraron en la guerra el 6 de abril. Su ejemplo fue imitado por otros países americanos como Perú, Bolivia y Brasil. León y Castillo, propuso formalmente, por primera vez, la ruptura de relaciones con Alemania, poner todos los recursos materiales y puertos al servicio de los Aliados, incrementar la producción de guerra y confiscar las propiedades y buques de los Imperios Centrales, a cambio de entablar negociaciones sobre Tánger, Gibraltar y Portugal. Ver ROMANONES, "Carta a León y Castillo", 6 de febrero de 1917, II I A, ACR; "Discusiones del WAR CABINET", 8 y 11 de marzo de 1917, 23/2 y 24/7, GT.198, Cabinet Papers, NA. Ver también, Francisco J. ROMERO SALVADÓ, España..., op. cit., pp. 92-95; Eduardo GONZÁLEZ CALLEJA y Paul AUBERT, Nidos..., op. cit., pp. 286-289; Javier MORENO LUZÓN, Romanones..., op. cit., pp. 329-333.

93 ROMANONES, "Carta a León y Castillo", 14 de abril de 1917, II I A, ACR: "El hundimiento del San Fulgencio ha sido la gota de agua... El camino ya está trazado en la dirección que usted, desde hace tiempo, conoce....".

${ }^{94}$ Anón., Algunos datos sobre la guerra submarina, Madrid, Hijos de Tello, 1918, pp. 45-47.

95 VAUGHAN, "Despacho a Balfour", 12 de abril de 1917, 371-3035/75548, FO. Ver en el mismo sentido, ROMANONES, “carta al embajador ante la Santa Sede, Fermín Calbetón, 18 de abril de 1917, II I A, ACR.

${ }^{96}$ El rey dio seguridades a Francia que permitieron retirar tropas de la frontera, ofreció colaboración en Marruecos y la pronta entrega de convoyes de mulas y caballos. Véase, Juan PANDO, Un rey..., op. cit., pp. 100-102; Eduardo GONZÁLEZ CALLEJA y Paul AUBERT, Nidos..., pp. 268-273; HARDINGE, "despachos a Grey", 31 de Agosto y 14 de Septiembre de 1914, 371-2105/44855 y 49204, FO.

${ }^{97}$ ROMANONES: Notas..., p. 379.

HISPANIA NOVA., 15 (2017), págs. 416-442

DOI: https://doi.org/10.20318/hn.2017.3496 
beligerantes en territorio enemigo y, en 1915, Alfonso XIII estableció una Oficina Pro-Cautivos para desarrollar cuantiosas iniciativas humanitarias ${ }^{98}$. Sin embargo, la identificación de los enemigos del régimen con los Aliados y los halagos y promesas de los Imperios Centrales le comenzaron a inclinar hacia posiciones germanófilas. Pero sobretodo, la iniciativa de Romanones no sólo destruía de un plumazo su sueño de erigirse un día en árbitro de la paz sino que además amenazaba la supervivencia de la monarquía como ilustraba la revolución en Rusia y el rápido reconocimiento del nuevo Gobierno Provisional por los Aliados ${ }^{99}$.

La decisiva intervención del soberano en la crisis de abril de 1917 precipitó los acontecimientos. Una asamblea multitudinaria que reunió a unas 25.000 personas en favor de las potencias occidentales, celebrada en la plaza de toros de Madrid el 27 de mayo, le tildó de campeón de la germanofilia y principal obstáculo a la democratización del país y le advirtió que no tardaría en sufrir el mismo destino que Nicolás $\|^{100}$. Claramente preocupado por los sucesos en Rusia y la polarización ideológica en España, el rey instó al nuevo gobierno a ordenar la disolución de las Juntas desatando, en el proceso, la insubordinación de aquellas.

A pesar de su evidente crisis de hegemonía, a diferencia de Rusia, el régimen en España no experimentó deserciones fundamentales. En este momento histórico, Antonio Maura jugó un papel decisivo. Apóstol de la "revolución desde arriba", tras haber sido abandonado en 1913 por la mayoría de notables del Partido Conservador, Maura había sido apoyado por un movimiento bullicioso, sobre todo formado por jóvenes monárquicos, que incluso adoptó su nombre (Maurista). Según su hijo Gabriel, dado el nivel de desencanto con las elites gobernantes, gran parte de la derecha hubiese seguido a su padre incluso contra la corona en aquel momento ${ }^{101}$. Maura podía haber constituido el eslabón fundamental entre juntas y asamblea pues ambas buscaron su apoyo. Sin embargo, a pesar de su crítica mordaz del sistema, rechazó tajantemente apoyar iniciativas subversivas que podían amenazar la seguridad de la monarquía incluso contra la opinión de figuras dirigentes del Maurismo como el antiguo gobernador civil de Barcelona, Ángel Ossorio, e incluso sus hijos Gabriel y Miguel, quienes veían en la asamblea la posibilidad de llevar a cabo la revolución pacífica que el mismo Maura llevaba predicando durante años ${ }^{102}$.

98 OFICINA PRO-CAUTIVOS, 2788/1 y 15.624/17 (1915-1921), Reinado de Alfonso XIII, Archivo General del Palacio Real (AGPR). Juan PANDO, Un Rey..., op. cit., pp. 21-29; Victor Espinós Moltó, Alfonso XIII: Espejo de neutrales, Madrid, Revista de Archivos, 1977.

99 ROMANONES, Notas..., op.cit., pp. 384-385; JOCELYN GRANT, “despacho a Balfour", 5 de mayo de 1917, 3713033/96587, FO; HARDINGE, "despacho a Balfour", 7 de mayo de 1917, 371-3033/92.539, FO; "Una crisis Germanófila", España, p. 1, 26 de abril de 1917.

100 "Afirmación aliadófila y revolucionaria”, El País, p. 1, 28 de mayo de 1917.

${ }^{101}$ Gabriel MAURA y Melchor FERNÁNDEZ ALMAGRO, Por qué..., op. cit., p. 302.

102 Para la negativa de Maura a sumarse a la asamblea véase, Miguel MAURA, "carta a Antonio Maura", 24 de junio de 1917 y Gabriel MAURA, "cartas a Antonio Maura" 26 de junio, 3, 8, 13-14 de julio de 1917, 362/2, AAM; Ángel OSSORIO, "carta a Antonio MAURA", 9 de julio de 1917, 80, AAM; Gabriel MAURA y Melchor FERNÁNDEZ ALMAGRO, Por qué..., op. cit., p. 489; Antonio MAURA, "carta a Ángel Ossorio", 12 de julio de 1917, 397/7, AAM. Sobre las Juntas véase Gustavo PEYRÁ, "cartas a Maura", 20, 25 y 28 de junio de 1917, 389/10 y, 20 de junio de 1917, 402/22, AAM. Maura calificó a las Juntas de "engendro monstruoso de añeja depravación" (Gabriel MAURA y Melchor FERNÁNDEZ ALMAGRO, Por qué..., op. cit., pp. 488-489) e incluso rehusó recibir a un mensajero de la Junta de Barcelona al que dejó en la calle bajo un diluvio. Un análisis está en Francisco J. ROMERO SALVADÓ,

HISPANIA NOVA., 15 (2017), págs. 416-442

DOI: https://doi.org/10.20318/hn.2017.3496 
La inhibición de Maura facilitó el éxito de las autoridades durante una fase clave de reacción gubernamental. Más eficaz que sus enemigos habían supuesto, el Ministerio Dato apostó por una estrategia no exenta de cierto maquiavelismo, algo que como algunos autores han subrayado simplemente seguía la máxima que el fin (preservar el régimen) justifica los medios ${ }^{103}$. Consciente que a pesar de su retórica reformista, las quejas de las Juntas eran principalmente de tipo corporativo, aprobó rápidamente sus estatutos y junto al monarca comenzó a alabar su patriotismo y hacerles saber que sus demandas serían satisfechas ${ }^{104}$. Después, aprovechó el estallido de una violenta huelga ferroviaria en Valencia en julio $^{105}$, para arrastrar con su posición descaradamente partidista a favor de la patronal al movimiento obrero a ejecutar su amenaza de huelga general revolucionaria con el objetivo que ante el espectro de la revolución, los sectores moderados de la asamblea abandonarían su proyecto reformista, el ejército se vería obligado a aplastar los disturbios y el gobierno podría jactarse de haber salvado el orden social y preservado la neutralidad ${ }^{106}$. Al mismo tiempo, implementó una campaña de intoxicación de la opinión pública, acusando a sus enemigos de estar financiados por oro extranjero para impulsar una revolución, proclamar la república y entrar en la guerra ${ }^{107}$. De hecho, como el muy conservador embajador británico, Arthur Hardinge, se cansó de repetir, la Entente, dependiente del suministro regular de minerales españoles para su esfuerzo bélico, rechazaba cualquier iniciativa que pudiese conllevar la desestabilización del país ${ }^{108}$. Pero, el caso de Grecia donde presiones franco-británicas acababan de destronar al germanófilo Rey Constantino I, casado con una hermana del Káiser (Sofía), parecía confirmar la tesis del juego malévolo de los Aliados ${ }^{109}$. Además, la francofilia de republicanos y socialistas facilitaba la verosimilitud de los infundios y, por consiguiente, su aceptación por la corona y en círculos militares ${ }^{110}$. Una vez estallada la huelga revolucionaria, las tropas, habiendo escapado la experiencia traumática de la guerra, obedecieron las órdenes de sus oficiales. Promesas de mejoras salariales junto a los rumores esparcidos

"Antonio Maura: el gran incomprendido", Alejandro QUIROGA y Miguel Ángel del ARCO BLANCO (eds.), Soldados de Dios y apóstoles de la patria. Las derechas españolas en la Europa de entreguerras, Comares, Granada, 2010, pp. $15-18$.

${ }^{103}$ Gerald MEAKER, The Revolutionary..., op. cit., p. 83; Carlos SECO SERRANO, La España de Alfonso XIII, Madrid, Espasa Calpe, p. 409.

104 Gobernador Civil de Barcelona, Leopoldo MATOS, “correspondencia con militares", 3115/28-31, Archivo de Leopoldo Matos, Archivo Histórico Nacional (AHN).

105 Los orígenes de este episodio son muy polémicos e incluyen rumores sobre la posible actuación de agentes provocadores en el estallido de la disputa. Socialistas como Manuel CORDERO (Los Socialistas y la revolución, Madrid, Torrent, 1932, pp. 30-33) y Andrés SABORIT (La huelga..., op. cit., p. 67) culparon a dirigentes republicanos valencianos.

106 "Instrucciones del ministro de la Gobernación", 8-12 de agosto de 1917, 42A/1, Serie Gobernación, AHN; Francisco J. ROMERO SALVADÓ, “La crisis..., op. cit.”, p. 77; José BUXADÉ, La bullanga..., op. cit., pp. 218-30.

107 Dato incluso comentó públicamente que los dirigentes obreros nadaban en oro y bebían champagne francés. Ver Gabriel MAURA, "carta a Antonio Maura", 7 de julio de 1917, 362/2, AAM.

108 "Un diplomático, aliado y amigo de España", La Época, p. 1, 4 de junio de 1917; Arthur HARDINGE, "carta a Emilio de las Torres, secretario del rey", 4 de julio de 1917), 15.892/25, AGPR; Arthur HARDINGE: A Diplomatist in Europe, Londres, Jonathan Cape, 1927, pp. 258-259.

${ }^{109}$ Aupado al poder el antiguo primer ministro, Eleftherios Venizelos, conocido por su política intervencionista en favor de los Aliados, Grecia entró en la guerra en julio de 1917.

${ }^{110}$ Francisco J. ROMERO SALVAdÓ, España..., pp. 155-157; Eduardo GONZÁLEZ CALLEJA y Paul AUBERT, Nidos..., pp. 294-298.

HISPANIA NOVA., 15 (2017), págs. 416-442

DOI: https://doi.org/10.20318/hn.2017.3496 
por el gobierno, incluyendo el infundio que la policía había detenido a los miembros del comité de huelga en un apartamento lujoso y en posesión de millones de pesetas y moneda extranjera, les llevó a concluir que era mejor ametrallar obreros que irse a cavar trincheras a Francia ${ }^{111}$.

Sus protagonistas son naturalmente un elemento crucial en cualquier proceso revolucionario. Es en este contexto, el caso ruso no tiene parangón con sus homólogos en Europa. Los Bolcheviques nacieron de una escisión del Partido Social Demócrata Ruso durante un congreso en el exilio en Londres en 1903. En contra de la facción rival o Menchevique cuyo objetivo era la creación de un partido socialista de corte europeo, con arraigo parlamentario y gran fuerza sindical, el Bolchevismo sería en palabras de su líder Lenin un partido centralizado formado por una elite de profesionales de la revolución ${ }^{112}$ En sus Lecciones de Octubre, Trotsky subrayó el papel fundamental del liderazgo para el éxito de la revolución: sin la férrea determinación de Lenin la historia de la revolución rusa podría haber sido muy diferente ${ }^{113}$. Tras su llegada del exilio, sus Tesis de Abril en que demandaba todo el poder para los Soviets desataron un terremoto político que brevemente incluso le aislaron en el seno de su propio partido. Según Lenin, la gran paradoja de la revolución era que el poder ya estaba en las manos de los soviets pero los líderes de los partidos entonces dominantes en el campo revolucionario, Mencheviques y Socialistas Revolucionarios $(\mathrm{SRs})^{114}$, rehusaban ejercerlo y permitían la existencia de un gobierno dominado por elementos monárquicos que posponía la discusión de las acuciantes demandas populares cuestiones en aras de la prosecución de la guerra imperialista ${ }^{115}$. Esa situación paradójica llegó a un clímax en julio cuando manifestaciones masivas estallaron en Petrogrado contra la impopular guerra e instando a los Soviets a tomar el poder. Concluyendo que la insurrección podía triunfar en la capital pero no contaba con apoyos sólidos en el resto del país, Lenin se opuso a que su partido encabezase la revuelta. Una vez reprimidos los disturbios por tropas del frente, Lenin tuvo que huir a Finlandia y algunos dirigentes Bolcheviques fueron encarcelados, pero el partido pudo seguir funcionando ${ }^{116}$ Poco después, el

111 "Embaucadores y embaucados", La Época, p. 1, 19 de agosto de 1917: la policía arresta a Arthur HARDINGE, "despachos a Balfour", 24 y 31 de agosto de 1917, 185/1346-371 y 433, FO; Mauro BAJATIERRA, Desde las barricadas..., op. cit., p. 29.

112 La táctica de LENIN fue inicialmente expuesta en febrero de 1902 en What is to Be Done?, Londres, Penguin, 1988, pp. 162-212. Jonathan D. SMELE, Historical..., op. cit., Vol. 1, pp. 213-214.

113 Leon TROTSKY, The Lessons..., op. cit., pp. 49-53.

114 Establecido en 1898, el Partido Social-Demócrata ruso se escindió en agosto de 1903 durante un congreso celebrado en el exilio en Londres. La facción Menchevique (del ruso menshinstvo o minoría) abogaba por un partido de masas siguiendo los pasos de la social-democracia europea, mientras la Bolchevique (de bolshinstvo o mayoría) inspirado en la tradición nihilista rusa defendía la idea de un partido pequeño formado por devotos profesionales de la revolución. El Partido Socialista Revolucionario, fundado en 1901, se auto-definía como el representante de las reivindicaciones ancestrales del maltratado pueblo y de la masa campesina. A diferencia de los marxistas, rechazaba el capitalismo y defendía un vago ideal colectivista (la implantación de una sociedad socialista, rural e idílica) y apoyaba tácticas terroristas en su lucha contra el estado zarista. Jonathan D. SMELE, Historical... op. cit., Vol. 2, pp. 735-736, 1072-1075.

${ }^{115}$ Vladmir I. LENIN, The Tasks of the Proletariat in Our Revolution, Londres, Lawrence \& Wishart, [1917], pp. 3-51. Según Trotsky (The History..., op. cit., Vol. 1, p. 312), el órgano de prensa Bolchevique, Pravda, publicó una nota alegando que "tales tesis no representaban sino la opinión particular de Lenin". Ver Robert SERVICE, Lenin, $A$ Political Life, Londres, Macmillan, 1995, Vol. 2, pp. 155-156; Christopher READ, From Tsar..., op. cit., pp. 152-153.

${ }^{116}$ Las jornadas del 16 al 18 de julio son enormemente confusas. En realidad, la insurrección en la capital fue como en marzo espontánea. Los Bolcheviques (como los Mencheviques y SRs) se vieron sorprendidos por su intensidad.

HISPANIA NOVA., 15 (2017), págs. 416-442

DOI: https://doi.org/10.20318/hn.2017.3496 
descalabro de la ofensiva militar seguido de la intentona fallida de golpe de estado lanzada a principios de septiembre por el comandante-en-jefe, General Lavr G. Kornilov, impulsó la radicalización sociopolítica ${ }^{117}$. Para entonces, tanto los Mencheviques como los SRs estaban fragmentados y habían visto como secciones o destacados militantes como el antiguo Menchevique Trotsky entraban en la órbita del Bolchevismo ${ }^{118}$. En octubre, los Bolcheviques habían ganado mayorías en los Soviets de las ciudades más importantes incluyendo Petrogrado cuya presidencia pasó a las manos de Trotsky. Desde ese momento, dadas las condiciones históricas, Lenin no dejó de instar a sus compañeros para poner en práctica el arte de la insurrección teniendo, en el proceso, que vencer la resistencia de algunos miembros del comité central. El golpe, llevado a cabo por el Comité Revolucionario Militar (la fuerza armada del Soviet a la que habían declarado su lealtad los regimientos de la guarnición de la capital) tomó el poder sin apenas resistencia la noche del 6 de noviembre de $1917^{119}$.

Radicalmente diferentes al Partido Bolchevique, los socialistas españoles eran, como los Mencheviques y otros partidos marxistas europeos de la II Internacional, políticos reformistas y miembros de la burocracia sindical, anclados en la comodidad del determinismo económico y el radicalismo del discurso oficial. En la práctica, en vez de preparar la distante revolución, perseguían una estrategia gradualista que al tiempo que implicaba una cierta aceptación de la legalidad imperante, les permitía consolidar ciertas parcelas de influencia en el mundo sindical, la vida municipal y - apenas en el caso español - la política estatal ${ }^{120}$. Los socialistas españoles estuvieron encantados de apoyar el proyecto reformista encarnado por la asamblea y liderado por la Lliga, un partido que no buscaba el asalto a la Bastilla sino conseguir pacíficamente una revolución política para impedir una convulsión social mucho más profunda que se temía estallaría tarde o temprano bajo un régimen desacreditado e impopular ${ }^{121}$. Su líder, Francesc Cambó, llegó a decir que "dadas las circunstancias, lo más conservador era ser revolucionario" ${ }^{122}$. De hecho, los dirigentes de la Lliga buscaron la colaboración de Maura y sus seguidores pues eran conscientes que sin su concurso, la asamblea sería descalificada desde fuentes

El dirigente Menchevique SUKHANOV (The Russian..., op. cit., pp. 429-431) destacó la ceguera de sus compañeros de insistir en contra de las masas de compartir el poder con la burguesía, masas que hasta ese momento apoyaban a Mencheviques y SRs.

${ }^{117}$ SUKHANOV (The Revolution..., op. cit., p. 524) confirma como tras el golpe de Kornilov secciones enteras de su partido en la capital y en las provincias se pasaron a los Bolcheviques.

${ }^{118}$ Desde septiembre de 1917, los llamados SRs de izquierda y los maximalistas actuaban independientemente del Partido Socialista Revolucionario y colaboraban con los Bolcheviques. Al mismo tiempo, los llamados Mencheviques-Internacionalistas también habían roto con el grupo dirigente de su partido. Jonathan D. SMELE, Historical... op. cit., Vol. 1, pp. 668-669 y Vol. 2, p. 737.

${ }^{119}$ La mayoría del comité central intentó demorar el lanzamiento de una insurrección llegando al extremo de quemar cartas de Lenin urgiéndoles a la acción. Compañeros del exilio como Grigorii Y. Zinoviev y Lev B. Kamenev incluso expresaron en el periódico Nóvaya Zhizn, dirigido por Maxim Gorki, su oposición a todo intento prematuro de tomar el poder por la fuerza. Lenin abandonó su refugio en Finlandia y volvió clandestinamente a Petrogrado el 23 de octubre donde forzó y gano el voto decisivo, no sin antes haber amenazado con dimitir y organizar el golpe por su cuenta con los militantes de base. Ver Robert SERVICE, Lenin..., op. cit., Vol. 2, pp. 212-215, 252-258.

${ }^{120}$ Paul HEYWOOD, Marxism..., op. cit., pp. 1-3; Santos JULIÁ, Los Socialistas en la política española, 1879-1982, Madrid, Taurus, 1997, pp. 16-49.

121 Juan Antonio LACOMBA, La crisis..., op. cit., p. 201.

122 Manuel BURGOS Y MAZO, Páginas..., op. cit., pp. 108-109.

HISPANIA NOVA., 15 (2017), págs. 416-442

DOI: https://doi.org/10.20318/hn.2017.3496 
gubernamentales de ser una iniciativa separatista y sediciosa y, por tanto, incapaz de ganar ninguna simpatía en los cuarteles ${ }^{123}$. Al mismo tiempo, siempre mantuvieron canales abiertos con el monarca quien llegó a insinuar que estaba dispuesto a presidir el fin del turno y conceder carteras ministeriales a los catalanistas si estos liquidaban la asamblea ${ }^{124}$.

Mientras los Bolcheviques, conscientes que el momento oportuno para tomar el poder no había llegado aún, frenaron a las masas en julio, un mes después, los socialistas españoles cayeron en la trampa urdida por el gobierno. Bajo la presión de sus socios de la $\mathrm{CNT}^{125}$ y enfurecidos tras agotar todos los canales para llegar a un compromiso en la huelga del transporte, abandonaron su prudencia habitual y acordaron declarar una huelga general revolucionaria dirigida por un comité formado por Julián Besteiro y Andrés Saborit (representantes del PSOE) y Francisco Largo Caballero y Daniel Anguiano (representantes de la UGT) que coordinase el movimiento con sus aliados republicanos y anarcosindicalistas ${ }^{126}$. Tras la rebelión pretoriana de junio y el desafío parlamentario de julio, había tal optimismo que, por una vez, los dirigentes socialistas rechazaron escuchar a Pablo Iglesias quien postrado en el lecho por enfermedad proponía un acto de solidaridad con los ferroviarios en vez de apoyar una huelga revolucionaria ${ }^{127}$. Estaban convencidos que como en Rusia el ejército desertaría al régimen. Los socialistas no querían subvertir el orden social sino proclamar una república democrática y progresiva. Un miembro del comité de huelga, Andrés Saborit, escribió que incluso hubieran permitido la continuidad de la monarquía si el rey aceptaba la reforma constitucional y democratización política ${ }^{128}$.Tal afirmación debe ponerse en entredicho. A pesar de todas las instancias en favor de calma, los socialistas estaban poniendo en marcha una huelga general revolucionaria y era natural que choques violentos estallasen cuando los piquetes intentaron paralizar las ciudades.

Como Serrallonga apunta, la falta de dirección precisa reflejaba las dificultades del socialismo español para hacerse súbitamente revolucionario tras años de acción legalista ${ }^{129}$. Apresuradamente lanzada, sin ninguna planificación, la huelga fue un fiasco. Muchos en la CNT se quedaron pasmados

${ }^{123}$ Francesc CAMBÓ, “carta a Gabriel Maura", 10 de julio de 1917, 19, AAM y Joaquín María NADAL, "carta a Antonio Maura", 11 de julio de 1917, 185, AAM.

124 Joaquín María NADAL, Memóries, $2^{\text {nd }}$ edn, Barcelona, Aedos, 1965, pp. 269-270; Ángel OSSORIO, “carta a Antonio Maura", 13 de julio de 1917, 362/2, AAM.

${ }^{125}$ La impaciencia de los dirigentes de la CNT quedó claro en sus encuentros en Barcelona con Pablo Iglesias y Francisco Largo Caballero en el verano de 1917. Ver Ángel PESTAÑA, Lo que aprendí..., op. cit., Vol. 1, pp. 60-63.

${ }^{126}$ La Federación Nacional de Ferroviarios, presionados por la UGT, estaba dispuesta a posponer una huelga general de solidaridad establecida para el 10 de agosto. La Compañía del Norte, apoyada por el gobierno, dio un ultimátum: la huelga iba a delante como previsto o rendición incondicional. Véase, "Acuerdo precipitado", El Socialista, p. 1, 8 de agosto de 1917; Andrés SABORIT, La huelga..., op. cit., pp. 67-69; discursos de miembros del comité de huelga en las Cortes en mayo de 1918 en Luis SIMARRO, Los sucesos..., op. cit.: Largo Caballero (pp. 913), y Daniel Anguiano (pp. 43-44).

${ }^{127}$ Para la posición de Pablo Iglesias ver Juan José MORATO, Pablo Iglesias, Barcelona, Ariel, 2000 [1931]), pp. 202203; el optimismo de los socialistas en Francisco LARGO CABALLERO, Mis recuerdos: Carta a un amigo, México, Ediciones Unidas, 1976, pp. 51-52; discursos de miembros del comité de huelga en las Cortes en mayo de 1918 en Luis SIMARRO, Los sucesos..., op. cit.: Largo Caballero (pp. 13-20), Saborit (pp. 50-51), Besteiro (pp. 175-176).

${ }^{128}$ Andrés SABORIT, La huelga..., op. cit., p. 8. Su desmarque total de la huelga fue publicado en un artículo titulado "Fals", La Veu de Catalunya, p. 2, 13 de agosto de 1917

${ }^{129}$ Joan SERRALLONGA, “Motines... op. cit.”, p. 187. 
cuando el dirigente socialista en Bilbao, Indalecio Prieto, sin ningún rubor, explicó en las Cortes en 1918 que para evitar desmanes se habían asegurado que aquellos obreros que tuviesen armas no recibiesen municiones ${ }^{130}$. Sólo tuvo cierto éxito en los grandes centros urbanos y zonas mineras, pero apenas tuvo impacto en el resto del país. A pesar que la revolución se hacía con el objetivo de implementar su programa, los dirigentes de la Lliga pronto dejaron claro que no tenían nada que ver con los hechos. Como sus homólogos en el Gobierno Provisional ruso, aunque se habrían apresurado a reclamar la dirección del nuevo régimen si se les hubiese entregado en bandeja, no se encontraban a gusto asociados con disturbios callejeros ${ }^{131}$. Confiados en la simpatía de las tropas, instrucciones habían sido cursadas a los obreros a proceder con caución y dar vítores al ejército, pero el movimiento fue ahogado en sangre incluyendo la utilización de artillería y el ametrallamiento indiscriminado de los manifestantes ${ }^{132}$.

\section{A MODO DE EPÍLOGO}

Aprovechando la falta de harmonía entre sus diferentes protagonistas, el régimen consiguió derrotar en 1917 el desafío tanto en su forma reformista (asamblea) como revolucionaria (huelga obrera). Gerald Meaker sugiere que el desenlace podría haber sido muy diferente en las postrimerías de la Gran Guerra cuando el ciclo revolucionario habría confluido con un simultáneo movimiento insurreccional en el campo andaluz ${ }^{133}$. Tal tesis, sin embargo, es difícil de sostener. En los años inmediatamente después del armisticio, gran parte de Europa vivió un periodo inusitado de agitación social espoleado por el ejemplo soviético y la profunda convulsión socio-económica. No obstante, en todas partes se saldó con un fracaso rotundo. De hecho, la gran paradoja de la Revolución Bolchevique no fue sólo su fracaso en exportar su modelo sino que la democracia liberal no fue víctima del tan temido espectro rojo sino de la marcha triunfal de la reacción.

Lacomba concluye que el régimen de la Restauración sobrevivió formalmente la experiencia de 1917 pero a nivel orgánico estaba formalmente liquidado ${ }^{134}$. De hecho, los militares se sintieron mortificados cuando el consejo de ministros, abrumado por la escala de la represión, intentó por todos los medios distanciarse de los sangrientos acontecimientos ${ }^{135}$. Conscientes de haber sido manipulados a reprimir una revuelta que el mismo gobierno había provocado, el 26 de octubre, entregaron un documento al rey pidiendo la destitución del Ministerio Dato. A cambio, sellaban la íntima comunidad de intereses con

\footnotetext{
${ }^{130}$ El discurso de Prieto está en Luis SIMARRO, Los sucesos..., op. cit., pp. 108-109; y la estupefacción de los cenetistas en Manuel BUENACASA, El movimiento obrero español, 1886-1926, Gijón, Júcar, 1977, p. 50.

${ }^{131}$ ibídem, p. 8.

132 “Juntas y Movimiento Revolucionario de 1917", agosto-octubre de 1917, AED. Ver también, Fernando SOLDEVILLA, El año..., op. cit., pp. 373-385; Juan Antonio LACOMBA, La crisis..., op. cit., pp. 260-265; José BUXADÉ, La bullanga..., op. cit., pp. 247-250.

${ }^{133}$ Gerald MEAKER, The Revolutionary..., op. cit., p. 94.

134 Juan Antonio LACOMBA, "Hundimiento del artilugio canovista”, Historia 16, no. 55 (1980), pp. 66-71; Juan Antonio LACOMBA, La crisis..., op. cit., p. 287.

135 Miguel MAURA, "cartas a Antonio Maura”,16-17 de agosto y 7 de septiembre de 1917, 362/2, AAM y Gabriel MAURA, "cartas a Antonio Maura, 16 y 20 de agosto de 1917, 362/2, AAM.
} 
la corona al garantizar la disolución de unas nuevas Cortes si representaban un desafío a la monarquía ${ }^{136}$. Este nuevo episodio de injerencia pretoriana en la vida pública era un golpe letal al orden constitucional y revelaba la precariedad de la soberanía civil. No obstante, si bien el desenlace final del ciclo revolucionario ilustraba la crisis del sistema gobernante también ilustró su capacidad de resistencia e incluso su adaptabilidad. De hecho, en 1917 el futuro estaba aún por determinar. Los partidos republicanos seguían siendo grupos relativamente pequeños, con escasa implantación fuera de unos pocos feudos urbanos. Traumatizados por la represión estatal, los socialistas rechazaron adherirse a nuevas aventuras revolucionarias, entraron en un proceso de recriminación mutua y luego de lucha intestina a causa de su posicionamiento hacia la nueva Internacional Comunista. Sin embargo, España se vio afectada como el resto de Europa por el clima de euforia revolucionaria, huelgas masivas y protesta popular estimulada por la dislocación socio-económica y el triunfo Bolchevique en Rusia. La CNT capitalizó la agitación obrera, experimentando en el proceso un crecimiento vertiginoso hasta alcanzar cerca de 700.000 miembros en 1919. No obstante, el movimiento anarco-sindicalista no representaba una verdadera amenaza al régimen. No era un partido férreo y organizado para tomar el poder como los Bolcheviques. Su desdén por la burocracia, énfasis en la acción directa y vaguedad ideológica quedaron gráficamente expuestos en su segundo congreso nacional en diciembre de 1919 que aprobó los principios del comunismo libertario a la vez que votaba por la afiliación a la recién creada Internacional Comunista. Simultáneamente, rechazó la creación de sindicatos nacionales de industria lo que suponía la persistencia de organizaciones regionales que en algunos casos (Cataluña, Andalucía, Valencia, etc.) tenían enorme fuerza pero carecían de núcleo central dirigente o de una estrategia de conquista del estado ${ }^{137}$. Por su lado, ambos partidos dinásticos se hallaban divididos en facciones y el turno pacífico, la base estructural del funcionamiento del sistema por casi 40 años, había quedado liquidado. Sin embargo, el parlamento siguió funcionando y el turno dio lugar a nuevas fórmulas de gobierno como la concentración monárquica que presidió el Marques de Alhucemas hasta marzo de 1918, y desde ese mes hasta noviembre un gobierno nacional presidido por el mismísimo Antonio Maura que contenía a todos los jefes de las principales facciones dinásticas. El régimen además mostraba su capacidad de absorber antiguas fuerzas de la oposición al incluir ahora a ministros de la Lliga ${ }^{138}$.

Ante la imparable realidad de una sociedad de masas, los partidos gobernantes fragmentados en facciones que iban desde el radicalismo de la Izquierda Liberal de Santiago Alba al conservadurismo nacionalista y católico de los Mauristas, tenían aun que hacer frente a su gran asignatura pendiente: una reforma política para refundar el régimen en significantes apoyos populares en vez del tradicional clientelismo. No obstante, un notable dinástico ya había dejado claro en octubre de 1917 el pavor a la democracia: "no es posible que un partido del turno haga suyo un programa que refleje la opinión de verdad del país... Con un voto libre de verdad no saldría ni un Liberal ni un Conservador elegido,

\footnotetext{
${ }^{136}$ Benito MÁRQUEZ y José María CAPÓ: Las juntas..., pp. 214-223; Carolyn P. BOYD, “El Rey-Soldado”, p. 228.

137 Confederación Nacional del Trabajo, Memoria del Congreso celebrado en el Teatro de la Comedia de Madrid, los días 10 al 18 de Diciembre de 1919, Toulouse, Portes \& San José, 1948, pp. 261-307, 373-374.

${ }^{138}$ En noviembre de 1917, la Lliga alcanzó dos de sus objetivos primarios: control de dos carteras ministeriales incluida la de Hacienda y la destrucción del monopolio político hasta entonces disfrutado por los partidos dinásticos. El análisis de contemporáneos y académicos hacia la táctica política de la Lliga oscila entre calificarla de pragmatismo o de mero gitaneo. Para un estado de la cuestión ver, Francisco J. ROMERO SALVADÓ, España..., op. cit., pp. 255-256 (nota 48).
}

HISPANIA NOVA., 15 (2017), págs. 416-442 DOI: https://doi.org/10.20318/hn.2017.3496 
especialmente en las grandes ciudades" ${ }^{139}$. Pero además de la disposición de las elites políticas a embrazar una reforma democrática, quedaba en vilo la posibilidad de llevarla a cabo. La supervivencia del régimen en 1917 había quedado hipotecada a la buena voluntad de la corona y las fuerzas armadas; y esta buena voluntad pronto se iba a poner a prueba ante lo que percibían como el inexorable avance del espectro rojo.

${ }^{139} 26$ de octubre de $1917,11-8904$, DNR. 